\title{
DESIGN OF GRID-WALL SOIL IMPROVEMENT TO MITIGATE SOIL LIQUEFACTION DAMAGE IN RESIDENTIAL AREAS IN URAYASU
}

\author{
Ichiro ISHII ${ }^{1}$, Ikuo TOWHATA², Ryoichi HIRADATE ${ }^{3}$, Shoichi TSUKUNI ${ }^{4}$, \\ Akihiko UCHIDA $^{5}$, Shun-ichi SAWADA ${ }^{6}$ and Takahiro YAMAUCHI ${ }^{7}$ \\ ${ }^{1}$ Member of JSCE, Deputy Mayor, Urayasu City (1-1, Nekozane, Urayasu, Chiba 279-8501, Japan) \\ E-mail: ishii.ichirou@city.urayasu.lg.jp \\ ${ }^{2}$ Fellow of JSCE, Visiting Professor, Kanto Gakuin University \\ (1-50-1, Mutsuurahigashi, Kanazawa-ku, Yokohama 236-8501, Japan) \\ E-mail: towhata.ikuo@gmail.com \\ ${ }^{3}$ Urayasu City Liquefaction Recovery Team, Urayasu City (1-1, Nekozane, Urayasu, Chiba 279-8501, Japan) \\ E-mail: fukkyuuproject@city.urayasu.lg.jp \\ ${ }^{4}$ Member of JSCE, Technology \& Production Development Division, Takenaka Civil Engineering \& Construction \\ Co., Ltd. (1-1-1, Shinsuna, Koto-ku, Tokyo 136-8570, Japan) \\ E-mail: tsukuni-s@takenaka-doboku.co.jp \\ ${ }^{5}$ Takenaka R \& D Institute, Takenaka Corporation (1-5-1, Otsuka, Inzai, Chiba 270-1395, Japan) \\ E-mail: uchida-akihiko@takenaka.co.jp \\ ${ }^{6}$ Member of JSCE, Engineering Headquarters, OYO Corporation (2-61-5, Toro, Kita-ku, Saitama 331-8688, Japan) \\ E-mail: sawada-shun@oyonet.oyo.co.jp \\ ${ }^{7}$ Member of JSCE, Civil Engineering Division, Maeda Corporation \\ (2-10-2, Fujimi, Chiyoda-ku, Tokyo 102-8151, Japan) \\ E-mail: yamauchi.tak@jcity.maeda.co.jp
}

\begin{abstract}
In the land reclamation areas of Urayasu City, 8,700 small buildings including residential houses suffered severe damage due to liquefaction during the 2011 Tohoku earthquake. Following this event, Urayasu City adopted grid wall soil improvements as countermeasures to mitigate liquefaction. For the simplified grid wall soil improvement design, the spacing between the grid walls is restricted within $L / H=0.8$, where $L$ is the spacing between the grid walls and $H$ is the thickness of the liquefaction layer. However, it is difficult to adopt $L / H$ as a design guideline because the grid wall soil improvement has to be applied underneath existing houses. The construction of grid walls directly underneath houses is impossible. Consequently, the spacing between the grid walls increases. It is suitable to use the settlement of a house as a design guideline for the conditions in Urayasu. Therefore, the following guideline was adopted. For a shock of the same magnitude as that of the main shock in the 2011 Tohoku earthquake in Urayasu no obvious damage must occur to a residential house. To meet this guideline, FL must exceeds 1.0 in all liquefied layers, or the index of settlement $D_{\text {cy }}$ must be within $5 \mathrm{~cm}$ and the non-liquefied layer $H_{1}$ must exceed $5.0 \mathrm{~m}$. The finite element method with a quasi-three-dimensional analysis model can be used to estimate the settlement of houses. However, there are no examples that have adopted the settlement as a design guideline in grid wall soil improvement design. Thus, dynamic centrifuge model tests were conducted to investigate the relationship between the settlement of houses and the grid area. Existing design guidelines for grid wall soil improvement use $F \mathrm{~L}$ or an excess pore pressure ratio. This study proposes a performance- based design method for grid wall soil improvement and verifies the validity of this approach.
\end{abstract}

Key Words : liquefaction, grid wall soil improvement, dynamic centrifuge model test

\section{INTRODUCTION}

In the 2011 Tohoku earthquake (Moment Magnitude $M_{w}=9.0$ ) many buildings suffered severe damage from tsunami. Furthermore, many residential houses suffered severe damage due to liquefaction. Liquefaction damage occurred at the riverside of the Tone river and the Tokyo Bay area, which were far from the epicenter. Total of 26,914 buildings in Japan suffered severe damage caused by liquefaction. 
Urayasu City is located in the Tokyo Bay area and is very small, covering an area of $17.3 \mathrm{~km}^{2}$ (Fig. 1). However, 8,700 buildings in the city suffered severe damage. This represents almost one third of all houses in Japan that suffered severe damage caused by liquefaction (Fig. 1). In Urayasu, the peak ground acceleration was $0.160 \mathrm{~g}$ (Fig. 2), which was relatively small. However, the duration of the seismic waves (hereafter called the Urayasu Wave) was about 200 seconds. Liquefaction was easily caused by the Urayasu Wave due to its long duration. The damaged area in Urayasu was restricted to land reclamation areas that were constructed using hydraulic dredging from 1965 to 1980 . The most severe damage occurred at the Nakamachi area. There were many residential houses in this area.

In 2011, the government planned a subsidy countermeasure project to mitigate liquefaction for residential houses and roads (Fig. 3). The Ministry of Land Infrastructure and Transport (MLIT) organized a committee composed of people with the required background knowledge and experience. MLIT also began to examine countermeasures to mitigate the effects of liquefaction in residential areas. In March 2014, three years after the Tohoku earthquake, MLIT published the city area liquefaction measures promotion guidance ${ }^{1)}$ (hereafter known as the MLIT Guidance). The guidance describes research methods through geological surveys, construction design using the groundwater level lowering method, and grid wall soil improvements.

The city government of Urayasu also organized a committee composed of people with the required background knowledge and experience (hereafter called the Urayasu Committee) on July 2011. Initially, the Urayasu Committee researched the relationship between the damage due to liquefaction and the ground properties. In 2012, the Urayasu Committee researched countermeasures to mitigate the effects of liquefaction using the groundwater level lowering method and grid wall soil improvements. The land reclamation area at Urayasu consists of several strata. The upper stratum is fill (F) constructed with dredge soil, and just below $F$ is loose holocene sand $\left(\mathrm{A}_{\mathrm{s}}\right)$. Soft and thick cohesive soil $\left(\mathrm{A}_{\mathrm{c}}\right)$ deposits are just below $A_{s}$. During a field trial using the groundwater level lowering method, disparate and large settlement of the ground surface was observed due to consolidation of inhomogeneous $\mathrm{F}$ stratum and $\mathrm{A}_{\mathrm{c}}$ stratum. Consequently, the city government of Urayasu adopted grid wall soil improvements as a countermeasure to mitigate liquefaction hazards. Figure 4 and Photo 1 show the concept of grid wall soil improvements. The im-

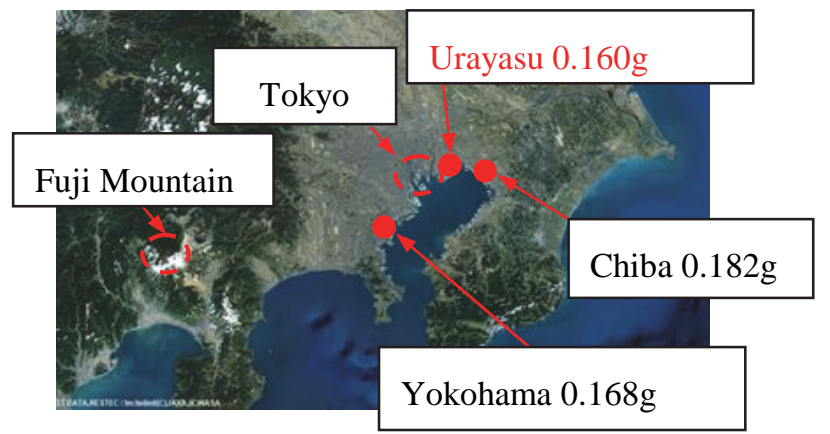

Fig. 1 Maximum horizontal acceleration due to the 2011 Tohoku earthquake in the Tokyo Bay area.

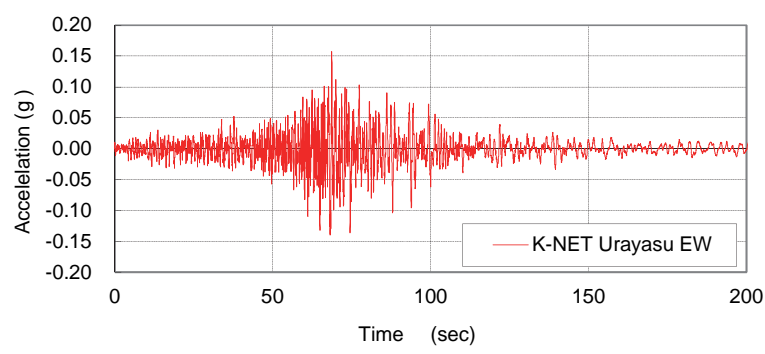

Fig. 2 Seismic wave observed in Urayasu (Urayasu Wave).

Grid-wall soil improvement

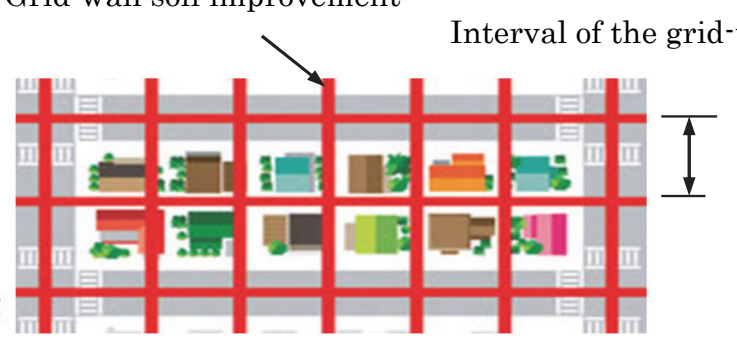

Fig. 3 A plan for grid wall soil improvement for roads and existing residential houses.

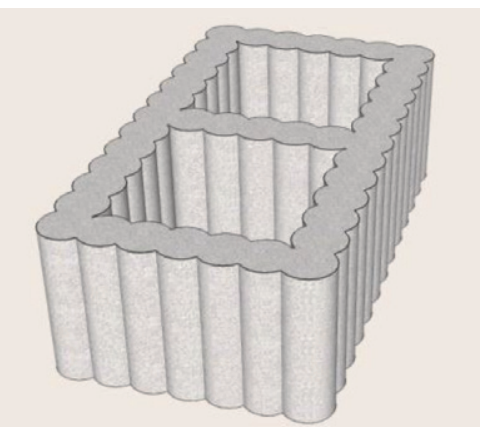

Fig. 4 Grid wall soil improvement.

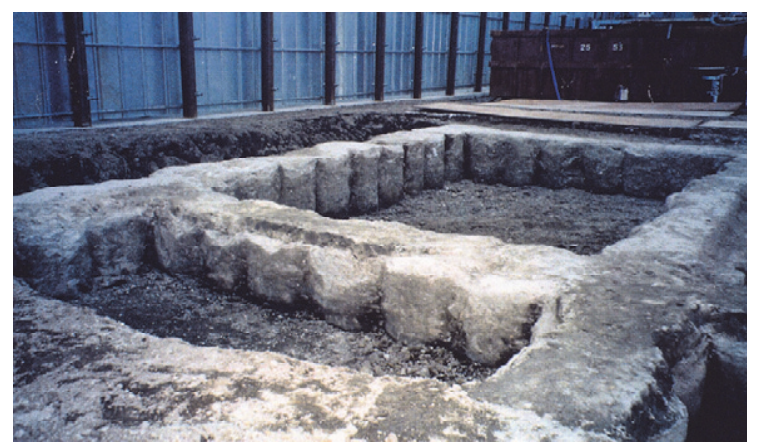

Photo 1 Grid wall soil improvement. 
proved soil walls surround the residential house's grid form shape in plan view. Grid walls are constructed using the deep cement mixing method and are composed of overlapping columns.

The existing design of grid wall soil improvement is based on guidelines using $F \mathrm{~L}$ or an excess pore pressure ratio. In this study, we propose a performance-based design method for grid wall soil improvement. The following design guidelines were adopted: (1) In a main target earthquake of the same magnitude as that of the 2011 earthquake, no obvious damage must occur to a residential house; (2) For a level 2 earthquake, the requirements are not defined to mitigate liquefaction but to set a stress for the improved soil. In particular, the shear stress of a grid wall must not exceed the permissible value. The requirements for a main target earthquake must also be satisfied for a level 2 earthquake. The finite element method (FEM) with a quasi-three-dimensional analysis model was used to design the grid wall soil improvement. The settlement of a residential house was used as a design guideline. As no previous approaches had used settlement as a guideline in the design of grid wall soil improvement, dynamic centrifuge model tests were conducted to investigate the relationship between the settlement of houses and the grid area. The design method and the numerical analysis were confirmed experimentally. In 2014, residents of Urayasu City agreed to develop plans and cost estimates for using grid wall soil improvements as a countermeasure. That plan was prepared for 4,103 residential houses in 16 districts. Geological surveys began in the same year. In 2015, the design of grid wall soil improvements began. If the residents agreed to the proposed plan and the estimated cost, the project would move to the construction stage. By March 2016, the plan and estimated cost had already been proposed to residents of 4,103 residential houses. The occupants of 44 residential houses agreed to move to the construction stage.

\section{DESIGN POLICIES}

This chapter describes the design method for grid wall soil improvements. Figure 5 explains the mechanism through which grid wall soil improvement mitigates liquefaction. The left part of the diagram shows the outcome without countermeasures, in which large shearing deformation of the ground occurs during an earthquake. The right part of the diagram shows the outcome with the use of grid wall soil improvement. Shear force concentrates on the

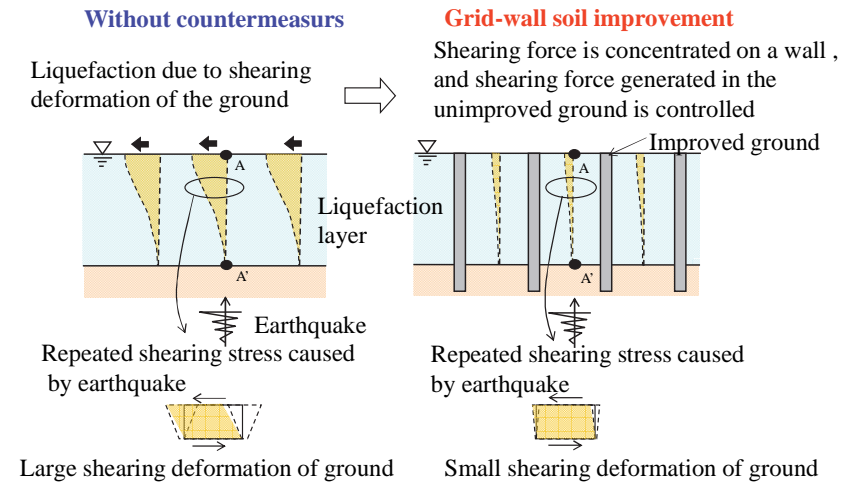

Fig. 5 Mechanism through which liquefaction is mitigated with the use of grid wall soil improvements.

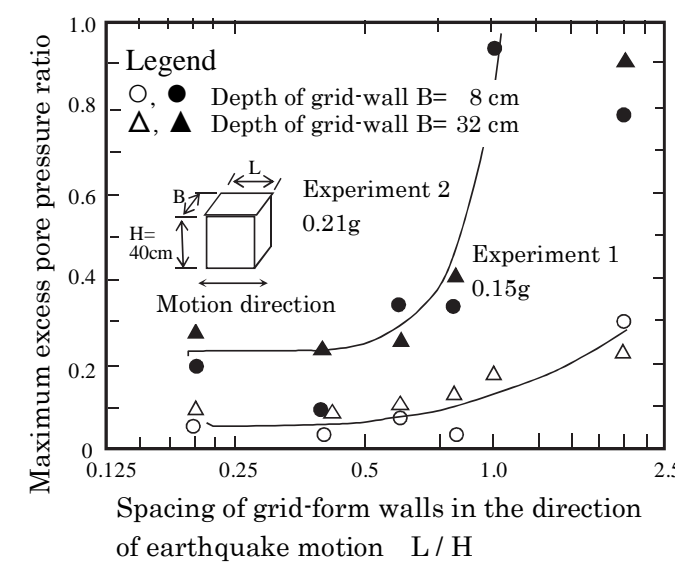

Fig. 6 Relationship between the spacing of grid walls and the maximum excess pore pressure ratio.

grid walls, thereby controlling the shear force generated in the ground. Development of the grid wall soil improvement technique was conducted from the late 1980 s to the early 1990 s.

Under the conditions of simplified grid wall soil improvement design, the spacing between the grid walls is restricted within $L / H=0.8$ according to experiments ${ }^{2), 3)}$. $L$ is the spacing between the grid walls, and $H$ is the thickness of the liquefaction layer. Figure 6 shows the relationship between $L / H$ and the maximum excess pore pressure ratio obtained through experiments. If $L / H$ is within 0.8 , the maximum excess pore pressure ratio is within 0.5.

Conversely, a detailed grid wall soil improvement design uses dynamic numerical analysis with the finite element method (FEM $)^{4)}$. The three-dimensional shape of grid walls are modeled using a two-dimensional analytical model. The shear stress generated in the ground is calculated from that produced by seismic waves. According to specifications ${ }^{5)}$, the calculated shear stress, the standard penetration test (SPT-) $N$ value, and the fine fraction content of soils (FC) give the liquefaction strength. Consequently, the safety factor against liquefaction (FL) can be calculated. During the 1995 Hyogo-ken Nanbu Earthquake, a hotel that adopted the detailed 
design method suffered no damage due to liquefaction $^{6}$. A theater in Urayasu also adopted the detailed design method, but had an $L / H$ that exceeded 0.8 . However, it also experienced no damage due to liquefaction ${ }^{7)}$. Considering these results, the city government of Urayasu adopted grid wall soil improvements as a countermeasure to mitigate liquefaction damage.

Some problems still remain in the application of grid wall soil improvement to residential areas in Urayasu. The main damage caused by liquefaction to residential houses was house inclination (Photo 2), because the bearing capacity of the ground decreased due to liquefaction. Because residents are living in a damaged or a repaired house, the grid walls will have to be built to roughly accommodate existing residential houses (it is not possible to construct the grid walls directly beneath the houses). Therefore, a grid wall has to be constructed between the spacing of residential houses. Due to such locations, the spacing between the grid walls will be relatively wide. One solution would be to allow partial liquefaction, thus increasing the feasibility and reducing the cost of countermeasures. Unfortunately, there are no quantifiable data on the relationship between the spacing of grid walls and ground settlement. To investigate this relationship, dynamic centrifuge model tests were conducted. The spacing between the grid walls was $16 \times 13 \mathrm{~m}$. The grid area was $208 \mathrm{~m}^{2}$, corresponding to typical conditions in the residential areas of Urayasu. For such typical conditions, dynamic centrifuge model tests confirmed the settlement of a residential house (within $50 \mathrm{~mm})^{8}$. The grid area of $208 \mathrm{~m}^{2}$ corresponds to one house existing in one grid. Therefore, the adopted design policy was to construct one grid for one residential house.

\section{GEOLOGICAL FEATURES AND SUR- VEYS}

Figure 7 shows the topographic division of Urayasu. The first group and the second group shown in Fig. 7 indicate that Nakamachi area's 16 districts consist of 4,103 residential houses. In Urayasu City (Shinmachi and Nakamachi), the land reclamation area was constructed using hydraulic dredging from 1965 to 1980. Before construction, a sea area was divided into three areas (sand bar, trough, and fairway). The sand bar was shallow and off the shore and was formed by the coastal current of the old Edo River. Inside the sand bar, a trough existed and a fairway was partially formed along the old Edo River. Photo 3 is an aerial photograph that was taken

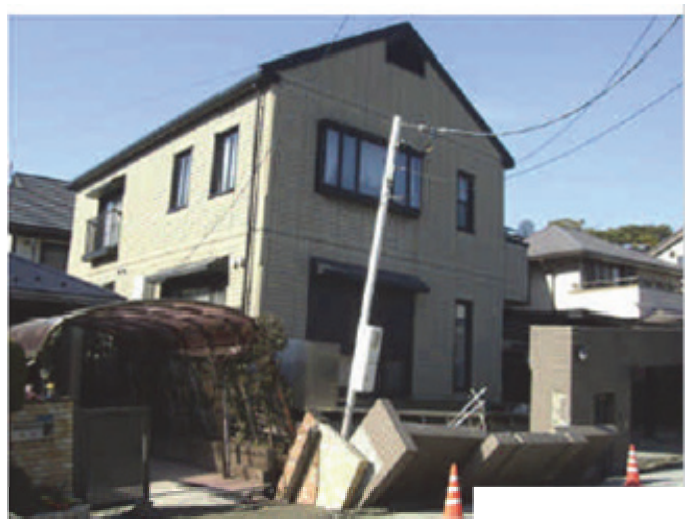

Photo 2 Damage to a residential house in Urayasu due to liquefaction during the Tohoku earthquake.

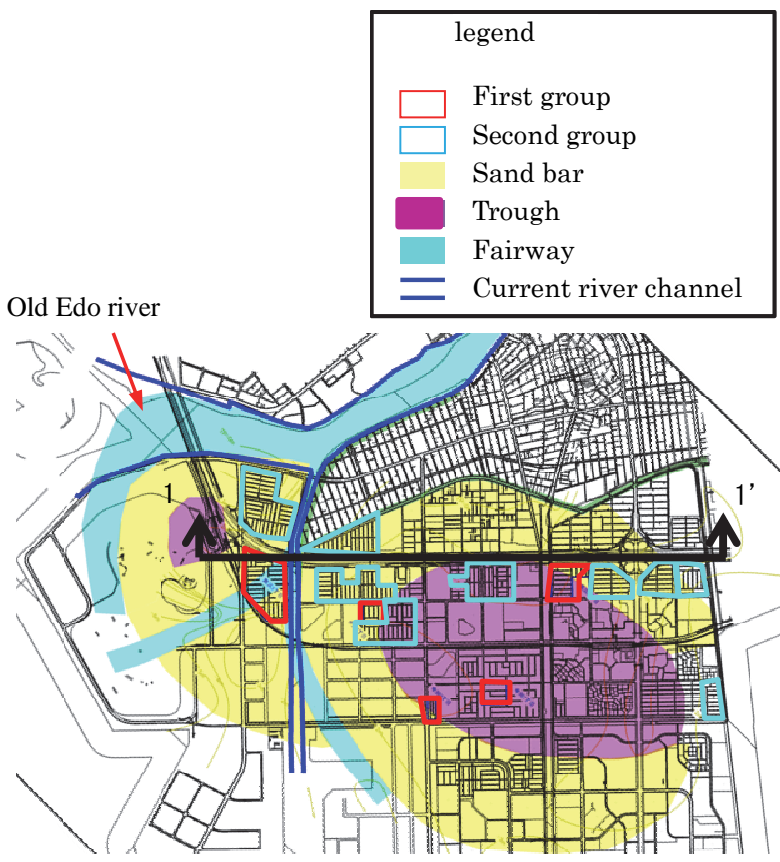

Fig. 7 Geological features.

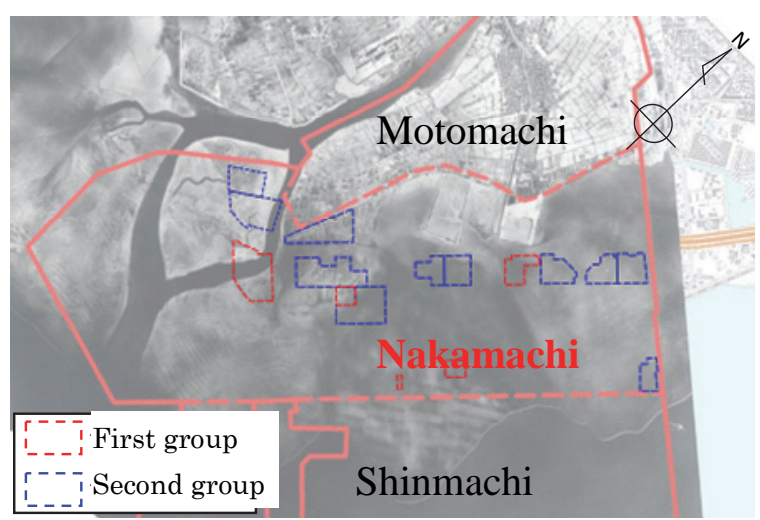

Photo 3 Aerial photograph taken in 1948 (before reclamation).

in 1948 (before reclamation). Table 1 shows the succession of the stratum for Urayasu. From the ground surface, stratum layers were divided into bank (B), landfill (F) constructed with dredged soil, holocene (A) composed of natural deposits, and pleistocene (D). According to an outline of the geo- 
logical section (Fig. 8), the shore platform (pleistocene) existed in a relatively shallow region on the right side of the section from district G. Conversely, a buried valley (holocene) existed in the deeper region around district $\mathrm{E}$.

To obtain information on soils needed to design grid wall soil improvements, boring and sounding surveys were conducted from the shallow region to the deeper region. The survey points are plotted in Fig. 9. From boring surveys from 119 points, in-situ tests and laboratory tests were conducted to obtain the geological characteristics. From sounding surveys for 281 points, the Piezo Drive Cone (PDC) test ${ }^{9)}$ was conducted to obtain the liquefaction strength of the shallow region. For the PDC test, a cone is continuously penetrated into the ground. At the same time, the penetration resistance and the excess pore pressure are observed at the top of the cone. Consequently, $N_{\mathrm{d}}$ (corresponding to SPT- $N$ ) and the fine fraction content of soils can be determined. The liquefaction strength can be calculated from the obtained $N_{\mathrm{d}}$ and the fine fraction content of soils. Survey results obtained from $50 \mathrm{~m}$ distance to $100 \mathrm{~m}$ distance provided the liquefaction strength of the $F_{s}$ stratum and the $A_{s}$ stratum. Geological survey results and the distribution of damaged residential houses after the 2011 Tohoku earthquake showed that liquefactions that occurred in the $\mathrm{F}_{\mathrm{s}}$ stratum and the $A_{s}$ stratum were the main reasons behind the damage caused to residential houses ${ }^{10)}$. Therefore, only the $\mathrm{F}_{\mathrm{s}}$ stratum and $\mathrm{A}_{\mathrm{s}}$ stratum data are required to calculate FL in the design of grid wall soil improvements.

\section{DESIGN CONDITION}

For the design of grid wall soil improvements for the Nakamachi area's 16 districts, the design conditions conform to the MLIT Guidance and consider the characteristics of Urayasu City.

\section{(1) Target of countermeasure}

Figure 10 shows the target of countermeasures and the level of damaged residential house based on the MLIT Guidance. $H_{1}$ on the horizontal axis indicates the thickness of the non-liquefied layer from the ground surface. Past earthquake damage investigations showed that there was no damage for residential house with a large enough value of $H_{1}{ }^{11)}$. The vertical axis $D_{\text {cy }}$ indicates the index of settlement due to liquefaction based on the Recommendation for Design of Building Foundations ${ }^{12)}$. $D_{\text {cy }}$ is also used in some guidelines on settlement caused by liquefaction. Damage to a residential house located in the A zone may be mitigated as shown in Fig. 10. After installation of grid wall soil improvement as a countermeasure to mitigate liquefaction, it is a minimum requirement that the final result be located in the A zone for earthquakes of the same level as that of the main shock of the 2011 Tohoku earthquake in Urayasu, and that $D_{\text {cy }}$ also does not exceed 5

\begin{tabular}{|c|c|c|c|c|}
\hline \multicolumn{2}{|c|}{ Geological age } & Stratum & $\begin{array}{l}\text { Stratum } \\
\text { symbol }\end{array}$ & Soil property \\
\hline \multirow{16}{*}{$\begin{array}{l}\text { Quaternary } \\
\text { period }\end{array}$} & \multirow{4}{*}{ Present age } & Bank & Bs & Sand (s) \\
\hline & & \multirow{3}{*}{ Landfill stratum (F) } & Fs & Sand (s) \\
\hline & & & $\mathrm{Fc}$ & Clay (c) \\
\hline & & & $\mathrm{Fcm}$ & Clay (c) \\
\hline & \multirow{6}{*}{ Holocene } & \multirow{6}{*}{$\begin{array}{l}\text { Yurakucho stratum } \\
\text { A (Alluvium) }\end{array}$} & As1 & Sand (s) \\
\hline & & & As2 & Sand (s) \\
\hline & & & Asc & Sand (s) / Clay (c) \\
\hline & & & Ac1 & Clay (c) \\
\hline & & & Acs & Clay (c) \\
\hline & & & Ac2 & Clay (c) \\
\hline & \multirow{6}{*}{ Pleistocene } & \multirow{3}{*}{$\begin{array}{l}\text { Nanagoti Formation } \\
\text { A (Holocene) }\end{array}$} & Ap & Peat (P) \\
\hline & & & Ac3 & Clay (c) \\
\hline & & & As3 & Sand (s) \\
\hline & & \multirow{3}{*}{$\begin{array}{l}\text { Kazusa stratum } \\
\text { D (Plestocene) }\end{array}$} & Dc & Clay (c) \\
\hline & & & Ds & Sand (s) \\
\hline & & & $\mathrm{D}_{\mathrm{SL}}$ & Sand (s) Vs $\geq 400 \mathrm{~m} / \mathrm{s}$ \\
\hline
\end{tabular}

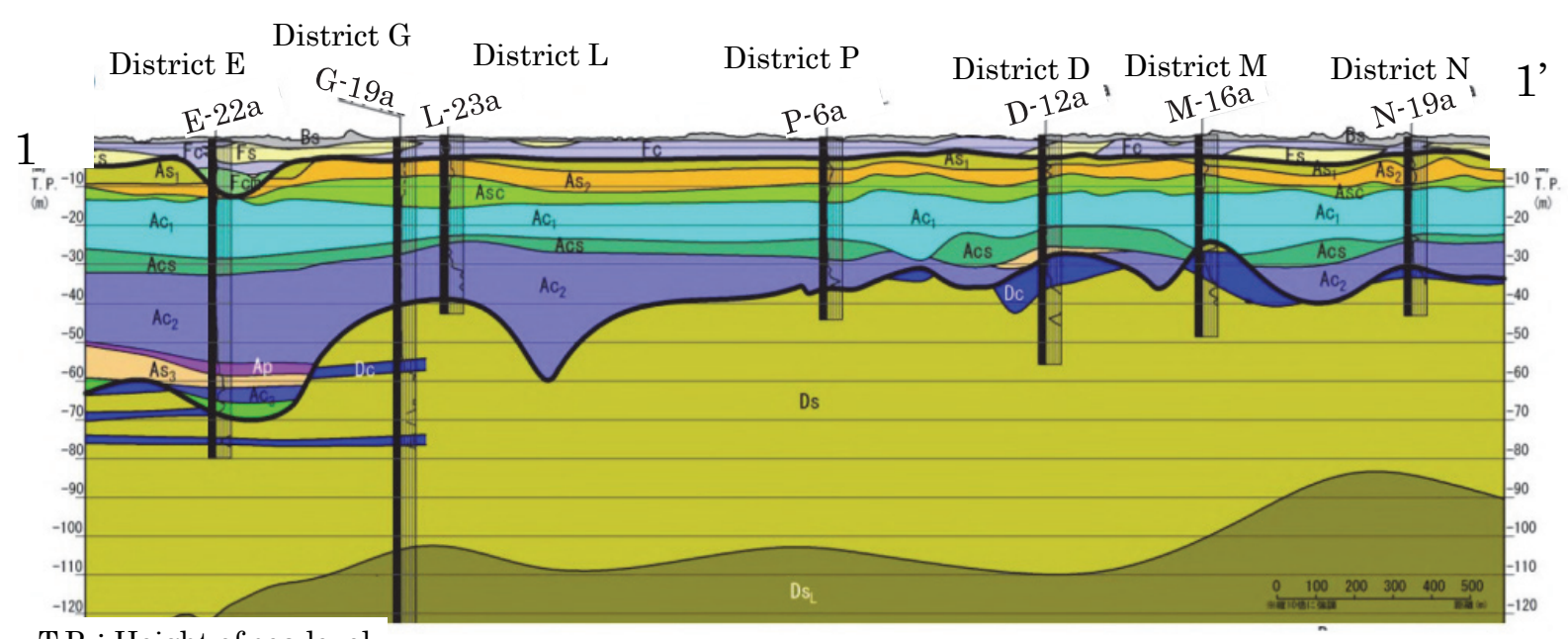

T.P. : Height of sea level

Fig. 8 Outline of geological section 1-1'. 


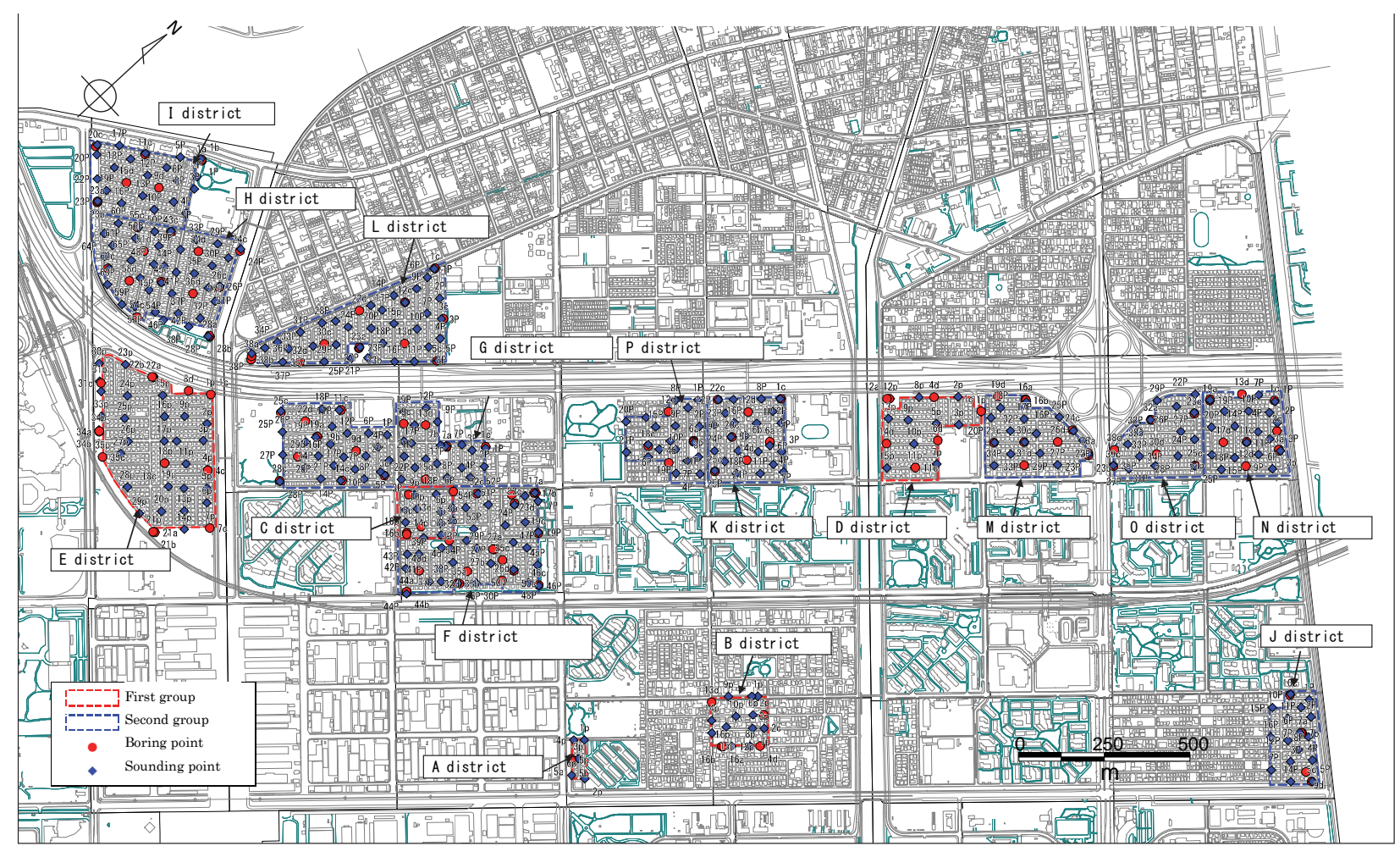

Fig. 9 Plan view of the survey points.

A : Low possibility of damage occurring

$\mathrm{B}$ : Relatively low possibility of damage occurring

$\mathrm{C}$ : High possibility of damage occurring

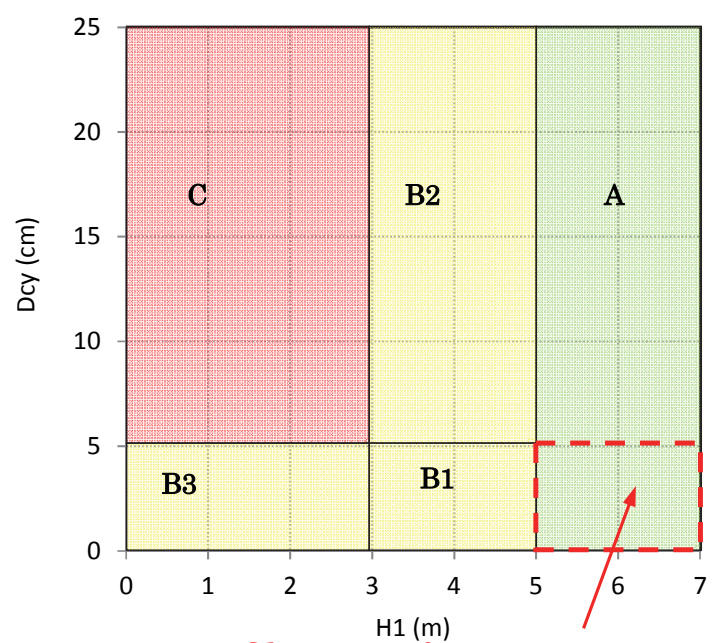

Objective of countermeasure

Fig. 10 Estimation of the damage to a residential house and the objective of countermeasures.

$\mathrm{cm}$. If the settlement of a residential house does not exceed $5 \mathrm{~cm}$, no damage is caused by the tilting of the house.

Table 2 shows the minimum requirement value for performance-based design of grid wall soil improvements. The main target earthquake for the design is of the same level as that of the main shock observed for the 2011 Tohoku earthquake in Urayasu. A level 2 earthquake corresponds to a local
Table 2 Minimum requirement values for performance based -design of grid wall soil improvements.

\begin{tabular}{|ccc|}
\hline Design earthquake & Requirement performance & Performance guideline \\
\hline Main target earthquake & $\begin{array}{c}\text { Occurrence of no obvious damage } \\
\text { due to liquefaction }\end{array}$ & $\begin{array}{c}\text { (1) } \mathrm{FL}>1.0 \text { in all liquefied strata } \\
\text { or }\end{array}$ \\
& (2)Dcy $\leq 5 \mathrm{~cm}$ and $\mathrm{H}_{1} \geq 5 \mathrm{~m}$ \\
Level 2 earthquake & $\begin{array}{c}\text { Maintain effectiveness of } \\
\text { countermeasures }\end{array}$ & $\begin{array}{c}\text { Occurred shear stress } \leq \text { Permissible } \\
\text { stress (improved soil) }\end{array}$ \\
\hline
\end{tabular}

Table 3 Design seismic waves.

\begin{tabular}{|ccc|}
\hline Design earthquake & Seismic wave & $\begin{array}{c}\text { Magnitude, } \\
\text { Peak acceleration (PA) }\end{array}$ \\
\hline Main target earthquake & $\begin{array}{c}\text { Yumenoshima wave } \\
\text { (observed in 2011.3.11) }\end{array}$ & $\mathrm{Mw}=9.0, \mathrm{PA}=0.109 \mathrm{~g}$ \\
Level 2 earthquake & $\begin{array}{c}\text { Northern part of Tokyo Bay } \\
\text { (simulated seismic wave) }\end{array}$ & $\mathrm{Mw}=7.3, \mathrm{PA}=0.426 \mathrm{~g}$ \\
\hline
\end{tabular}

earthquake. For the main target earthquake level, it is required that no obvious damage occurs for a residential house. To satisfy the above mentioned performance, the requirement value must either be that $F L$ exceeds 1.0 in all liquefied layer or that both $D_{\text {cy }}$ should be within $5 \mathrm{~cm}$, and $H_{1}$ should exceed $5.0 \mathrm{~m}$. For a level 2 earthquake, the requirement value is the stress level that occurs on the improved grid wall, that is , that the shear stress of the grid wall must not exceed the permissible value. The requirement value for a main target earthquake must be satisfied even after the occurrence of a level 2 earthquake.

\section{(2) Earthquake waves in the design process}

Figure 11 shows the wave of a main target earthquake that was estimated at the seismic bedrock in the engineering of Yumenoshima during the 2011 
earthquake. In design, the amplitude of the input motion to the seismic bedrock in engineering $\left(V_{\mathrm{s}} \geqq\right.$ $400 \mathrm{~m} / \mathrm{s}$ ) is adjusted to the peak ground acceleration as estimated from the peak ground acceleration during the 2011 Tohoku earthquake. The wave of a level 2 earthquake adopts a seismic wave recorded from the northern part of Tokyo Bay (Fig. 12). This earthquake wave is a simulated seismic wave of a local earthquake in Urayasu. The input motion amplitude at Nakamachi area's 16 districts has the same amplitude as shown in Fig. 12.

\section{(3) Soil parameters in design analysis}

The seismic response design analysis was conducted using equivalent linear analysis, which requires the following soil parameters: the unit weight, shear wave velocity $V_{s}$, and the dynamic properties of the ground. The unit weight adopted the average value obtained at the first group consisting of five districts, where geological surveys were previously conducted. In design analysis, the dynamic properties of the ground for the liquefied strata of $F_{s}, A_{s 1}$, and $A_{\mathrm{s} 2}$ were set up as shown in Fig. 13.

The groundwater level of each district was set up with the observed groundwater level at the boring point. However, the groundwater level was $0.5 \mathrm{~m}$ below the ground surface in the observed results, while the average groundwater level was almost 1.5 $\mathrm{m}$ below the ground surface. In analysis, considering seasonal variations, the groundwater level was set up to be shallower. Therefore, the groundwater level was adopted as $1.0 \mathrm{~m}$ below the ground surface for 10 of the 15 districts.

The thickness of the bank, called the $\mathrm{B}_{\mathrm{s}}$ stratum, was about $1.5 \mathrm{~m}$. The liquefaction strength of the $B_{s}$ stratum, which was obtained from Swedish weight sounding and cyclic triaxial test, was large enough to mitigate liquefaction damage during a main target earthquake. Therefore, the $B_{s}$ stratum was regarded as a non-liquefied stratum in the design. The $F_{c}$ stratum was also regarded as a non-liquefied stratum due to the relationship between the plasticity index and the content rate of the fine fraction content of soils obtained from laboratory tests. Assuming that the $B_{s}$ stratum and the $F_{c}$ stratum are regarded as non-liquefied stratums, $H_{1}$ from the ground surface exceeds $2.0 \mathrm{~m}$ in the major parts of 16 districts. The liquefaction strength of each district for the $F_{s}$ stratum, the $A_{s 1}$ stratum, and the $A_{s 2}$ stratum are shown in Table 4. The liquefaction strength was defined as a $3.75 \%$ shear strain with a simple amplitude with 15 cycles ( $R$ L 15), and the liquefaction strength adopted in design was the average value. Table 4 also shows the judgment result for liquefaction that was ob-
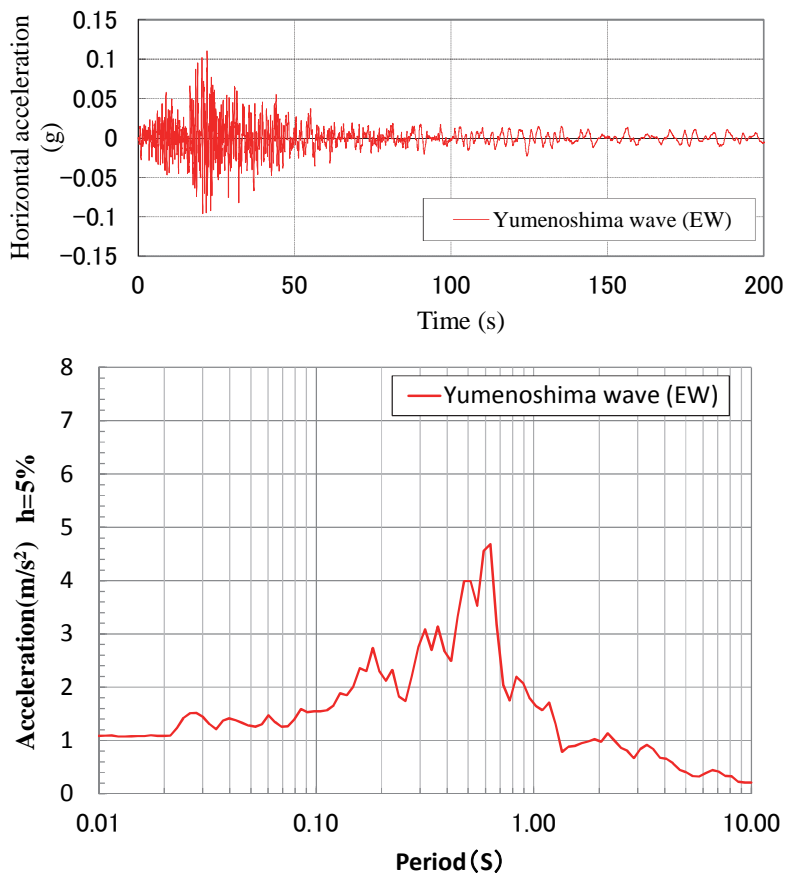

Fig. 11 Seismic wave and acceleration response spectrum (main target earthquake).
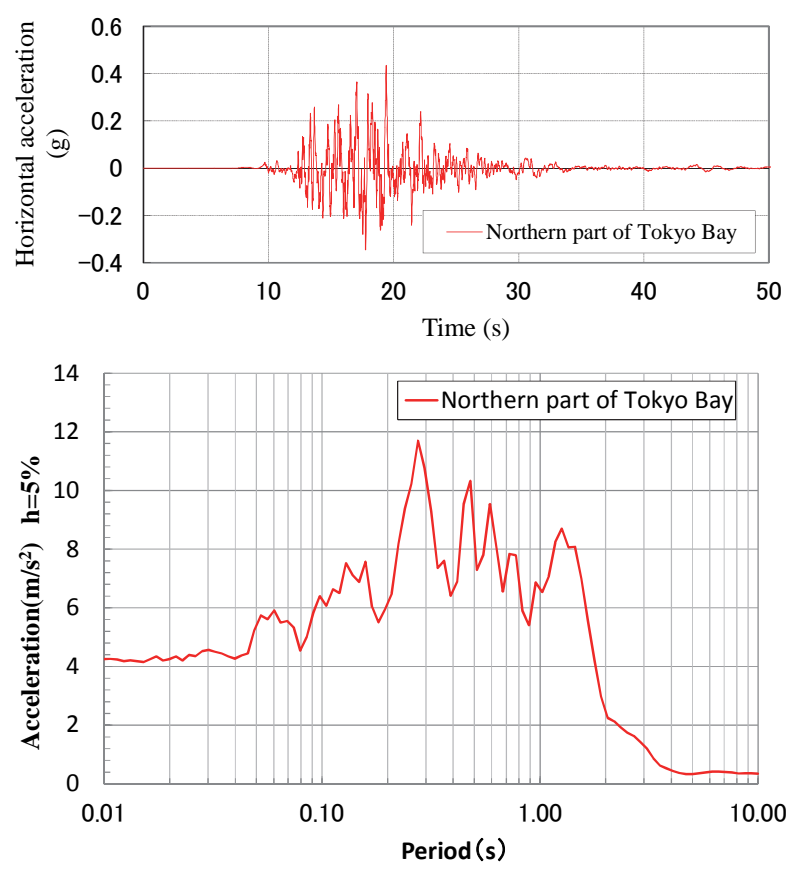

Fig. 12 Seismic wave and acceleration response spectrum (Level 2 earthquake).

tained from one-dimensional equivalent linear analysis. The input motion to the seismic bedrock in engineering of each district was set up for a peak ground acceleration of the same level as the estimated one (Fig. 14). Liquefaction occurs in the $F_{s}$ stratum in all 16 districts. Liquefaction occurs in the $A_{s 1}$ stratum in 4 of 16 districts. Liquefaction does not occur in the $A_{\mathrm{s} 2}$ stratum in 14 districts, and partial liquefaction occurs in the $A_{s 2}$ stratum of 2 districts. 
(4) Relationship between input earthquake motion and earthquake damage for a residential house

This section describes the selection method for the amplitude of a main target earthquake for each district's seismic bedrock in engineering. First, using boring data and PS logging, one-dimensional equivalent linear analysis was conducted for various amplitudes of the Yumenoshima Wave. The amplitude of the main target earthquake was set up to fit the obtained peak ground acceleration from an analytical estimated peak ground acceleration from the 2011 Tohoku earthquake. Figure 14 compares the estimated peak ground acceleration from the 2011 Tohoku earthquake and the calculated peak ground acceleration for each district. They are both almost the same. The estimated peak ground acceleration was calculated using one-dimensional equivalent linear analysis. Each district's estimated maximum acceleration was determined to fit the observed earthquake wave obtained from an accelerometer attached to a gas pipe.

Figure 15 shows the relationship between $H_{1}$ and $D_{\text {cy }}$ obtained from the above-mentioned one-dimensional equivalent linear analysis for boring test points in each district. Boring test points were chosen based on severe damage that occurred in residential houses during the 2011 earthquake. For the case with no countermeasures, $H_{1}$ is less than $5 \mathrm{~m}$
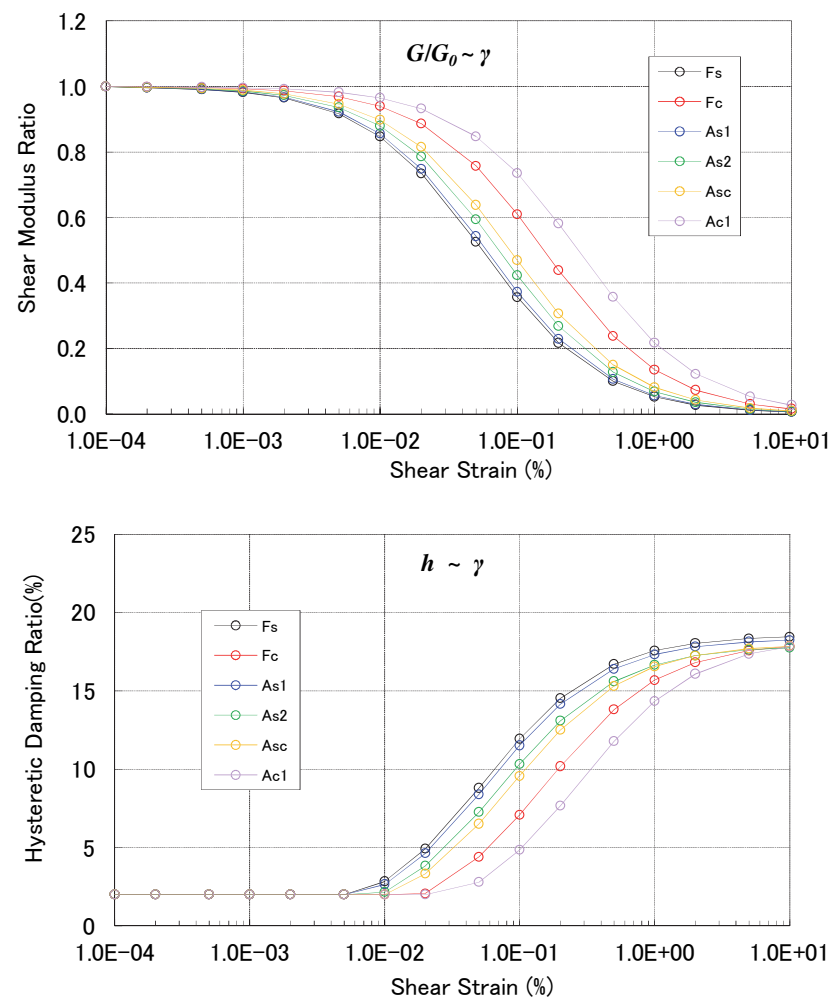

for all districts. Therefore, the countermeasure target for a main target earthquake is not satisfied in such a case.

\section{VERIFICATION OF NUMERICAL METHOD WITH MODEL GROUND CONDITIONS}

The Urayasu Committee chose the soil profile to consider the countermeasures to mitigate the effects of liquefaction in 2012 (Fig. 16). The model ground condition was to refer to the stratum structure of the

Table 4 Liquefaction strength and liquefaction occurrence.

\begin{tabular}{|ccccccc|}
\hline \multirow{2}{*}{ District } & \multicolumn{2}{c}{ Liquefaction strength (RL15) } & \multicolumn{3}{c|}{ Occurrence of liquefaction } \\
& Fs & As1 & As2 & Fs & As1 & As2 \\
\hline A & 0.171 & 0.210 & 0.279 & $\times$ & $\times$ & $\bigcirc$ \\
B & 0.147 & 0.182 & 0.256 & $\times$ & $\times$ & $\bigcirc$ \\
C & 0.162 & 0.248 & 0.241 & $\times$ & & $\bigcirc$ \\
D & 0.167 & 0.169 & 0.360 & $\times$ & $\times$ & $\bigcirc$ \\
E & 0.162 & 0.276 & 0.239 & $\times$ & & $\triangle$ \\
F & 0.178 & 0.203 & 0.241 & $\times$ & $\triangle$ & $\bigcirc$ \\
G & 0.217 & 0.251 & 0.282 & $\times$ & $\triangle$ & $\bigcirc$ \\
H & 0.199 & 0.190 & 0.319 & $\times$ & - & $\bigcirc$ \\
I & 0.201 & - & 0.253 & $\times$ & - & $\triangle$ \\
J & 0.209 & 0.172 & 0.267 & $\times$ & $\times$ & $\bigcirc$ \\
K & 0.148 & 0.190 & 0.375 & $\times$ & $\times$ & $\bigcirc$ \\
L & 0.184 & 0.230 & 0.259 & $\times$ & $\times$ & $\bigcirc$ \\
M & 0.180 & 0.174 & 0.486 & $\times$ & $\times$ & $\bigcirc$ \\
N & 0.215 & 0.175 & 0.259 & $\times$ & $\times$ & $\bigcirc$ \\
O & 0.184 & 0.181 & 0.286 & $\times$ & $\times$ & $\bigcirc$ \\
P & 0.148 & 0.187 & 0.478 & $\times$ & $\times$ & $\bigcirc$ \\
\hline × Liquefaction & $\triangle:$ Partial liquefaction & : Non-liquefaction & \\
\end{tabular}
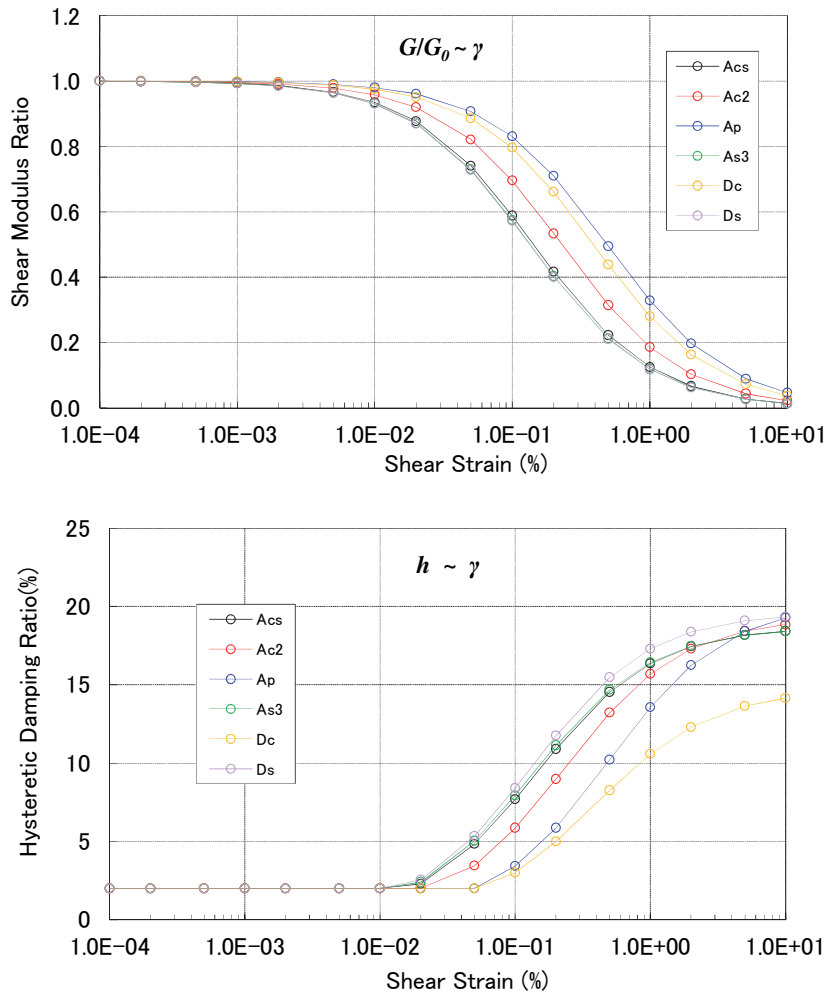

Fig. 13 Dynamic properties $G \sim \gamma$, and $h \sim \gamma$ (design analysis, laboratory test results). 
area where the most severe damage occurred due to liquefaction during the 2011 Tohoku earthquake. The stratum structure from the ground surface was $B_{s}$ stratum filled with mountain sand, $\mathrm{F}_{\mathrm{S}}$ stratum constructed with dredge soil, and $\mathrm{A}_{\mathrm{s} 1} \cdot \mathrm{A}_{\mathrm{s} 2}$ strata composed of natural deposits. Just below $A_{s 2}$, soft $A_{c}$ stratum was deposited $45 \mathrm{~m}$ below the ground level. The stratum structure of the 16 districts is similar to the model ground condition. Dynamic centrifuge model tests were conducted with the model ground conditions. According to the relationship between the grid area and the settlement of residential houses obtained from tests results, the analysis method for setting up the specifications of grid wall soil improvements was verified.

(1) Relationship between the grid area and the settlement of a residential house obtained from dynamic centrifuge model test results

Table 5 shows the liquefaction strength for the model's ground condition in Urayasu and from the experiments. In the experiments, the liquefied layer of the ground model was made using Toyoura sand and Urayasu sand. Urayasu sand was taken from erupted soil from Urayasu during the 2011 Tohoku earthquake. The liquefaction strength of the ground model in the experiment corresponded to the model's ground condition. The $D$ value for controlling the density of Urayasu sand was defined as the ratio for the maximum dry density $\left(\rho_{\mathrm{dmax}}=1.451 \mathrm{t} / \mathrm{m}^{3}\right)$. Toyoura sand was controlled using the relative density. Figure 17 shows the grain size distribution of Toyoura sand and Urayasu sand. The fine content of Urayasu sand was adjusted to $25 \%$ which corresponded to the fine content of the model ground condition.

The dynamic centrifuge model test is described in detail in the references ${ }^{8), 13)}$. The condition in the residential area of Urayasu were those from Case-6. Figure 18 shows the plan view and cross-section in Case-6 from which countermeasures and the without grid walls were modeled. The measurements were converted to an actual scale from the models. The dynamic centrifuge model tests were conducted for 60 times gravity. The spacing of grid walls was 16 and $13 \mathrm{~m}$, which one house existed in each grid. The spacing between the grid walls was defined as the distance from the center of the improved walls. The spacing between the residential house models was $2.0 \mathrm{~m}$, and the center of the improved wall was at 1.0 $\mathrm{m}$ from the residential house model. The liquefied layer was made with Urayasu sand. The grid wall soil improvement model was made of acrylic, with a width of $0.9 \mathrm{~m}$ (Young's modulus $E=1.47 \times 10^{3}$

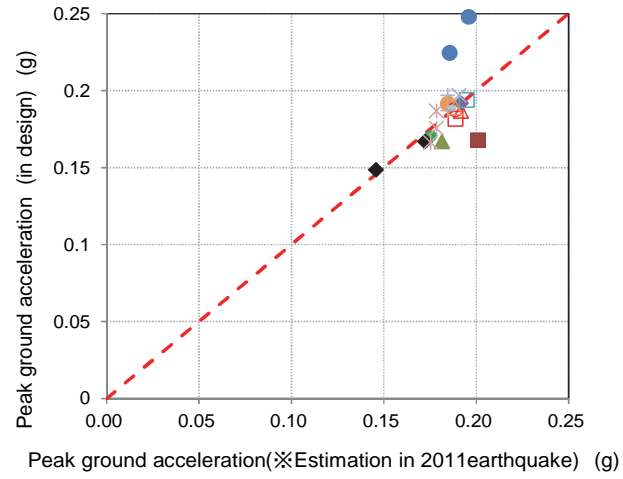

Fig. 14 Comparison of peak ground acceleration between estimations and design.

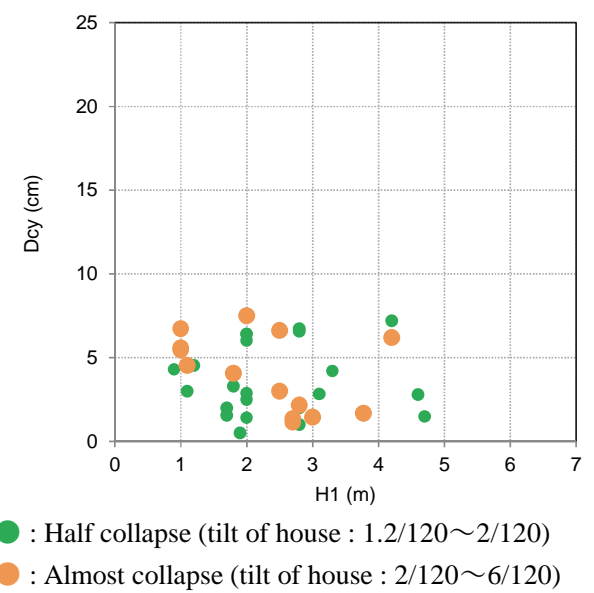

Fig. $15 H_{1}$ and $D_{\text {cy }}$ (without countermeasures).

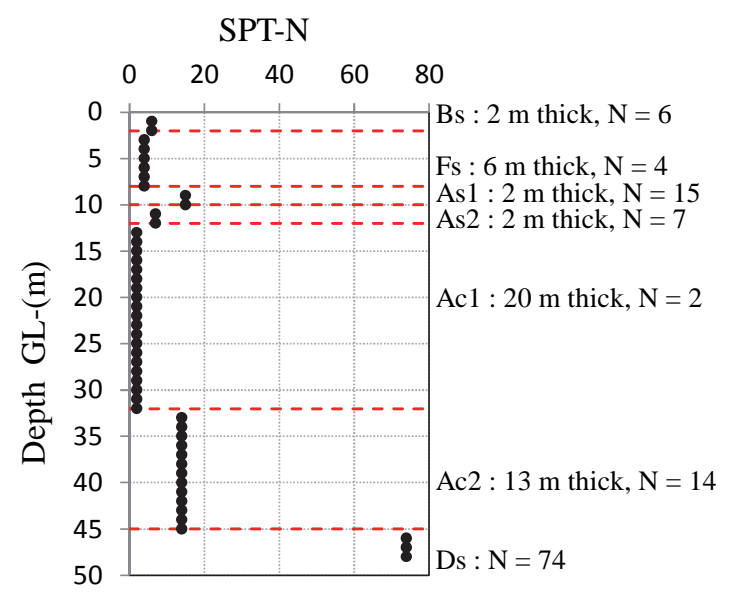

Fig. 16 Ground model conditions.

$\mathrm{MPa})$. The Young's modulus $E$ of acrylic corresponds to that of improved soil produced using the mechanical mixing method with a standard design strength $f_{\mathrm{c}}=1.5\left(\mathrm{~N} / \mathrm{mm}^{2}\right)$. An Urayasu Wave was inputted at the base of the shaking box. The model of the residential house had two stories, and the flat dimensions were $8.0 \mathrm{~m}$ (direction of earthquake motion) and $11.0 \mathrm{~m}$ (orthogonal to the direction of the earthquake). The contact pressure of the model residential house was $8.4\left(\mathrm{kN} / \mathrm{m}^{2}\right)$. 
Table 5 Liquefaction strength (ground model and experiments).

\begin{tabular}{|c|c|c|c|c|c|c|}
\hline & \multicolumn{2}{|c|}{ Urayasu ground model } & \multicolumn{4}{|c|}{ Experimental ground model } \\
\hline Depth (m) & Layer & $\begin{array}{c}\varepsilon a=2.5 \% \text {, Stress } \\
\text { ratio with } 20 \text { cycle } \\
\text { times }\end{array}$ & Layer & $\begin{array}{c}\varepsilon a=2.5 \%, \text { Stress } \\
\text { ratio with } 20 \text { cycle } \\
\text { times }\end{array}$ & Layer & $\begin{array}{c}\varepsilon a=2.5 \% \text {, Stress } \\
\text { ratio with } 20 \text { cycle } \\
\text { times }\end{array}$ \\
\hline $0-2 \mathrm{~m}$ & Bs & $\begin{array}{l}0.25 \\
0.20\end{array}$ & $\begin{array}{c}\text { Toyoura sand } \\
\text { Dr }=50 \%\end{array}$ & 0.17 & $\begin{array}{l}\text { Urayasu sand } \\
\text { D value }=90 \%\end{array}$ & 0.18 \\
\hline $8-10 \mathrm{~m}$ & As1 & 0.36 & $\begin{array}{c}\text { Toyoura sand } \\
\text { Dr }=70 \%\end{array}$ & 0.22 & $\begin{array}{l}\text { Urayasu sand } \\
\text { D value }=95 \%\end{array}$ & 0.28 \\
\hline
\end{tabular}

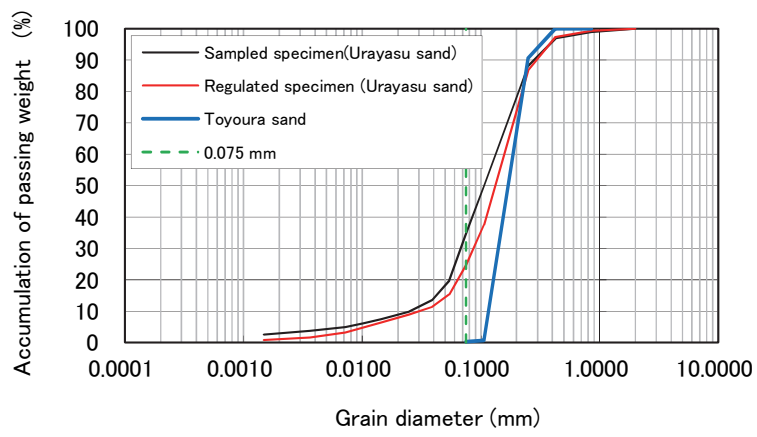

Fig.17 Grain size distribution for Urayasu sand and Toyoura sand.

An Urayasu Wave was observed at the ground surface of the non-liquefied area during the 2011 Tohoku earthquake. The observed point at the surface of the $A_{s}$ stratum was within the damaged area where the landfill $(\mathrm{F})$ with dredged soil was constructed above the holocene (A). Therefore, the observed Urayasu Wave corresponded to earthquake motion just below the liquefied layer.

Figure 19 shows the relationship between the grid area and the settlement of the residential house. The grid area was defined with the surrounding area of the center of improved soil. The area of the $16 \times 13$ $\mathrm{m}$ grid was $208 \mathrm{~m}^{2}$. The area of the $32 \times 13 \mathrm{~m}$ grid was $416 \mathrm{~m}^{2}$, and the area of the $32 \times 26 \mathrm{~m}$ grid was $832 \mathrm{~m}^{2}$. Since the grid area was small, the settlement of the residential house was minimal. The equivalent spacing $L$ ' between the grid walls was defined as the square root of the grid area. As the thickness of the liquefaction layer was $11 \mathrm{~m}$ in the experiments, $L^{\prime}$ / $H=1.31$ for a grid area of $208 \mathrm{~m}^{2}, L^{\prime} / H=1.85$ for a grid area of $416 \mathrm{~m}^{2}$ and $L^{\prime} / H=2.62$ for a grid area of $832 \mathrm{~m}^{2}$. Under the conditions of the $16 \times 13 \mathrm{~m}$ grid, the average settlement of the residential house was $50 \mathrm{~mm}$, and it was about $40 \%$ compared with that of the one without countermeasures. The average settlement of the residential house was almost the same for the case of Toyoura sand and for the case of Urayasu sand. In the case of a $20 \times 20 \mathrm{~m}$ grid, which has an area of $400 \mathrm{~m}^{2}$, the average settlement of the residential house was $71 \mathrm{~mm}$. The grid area of the 20

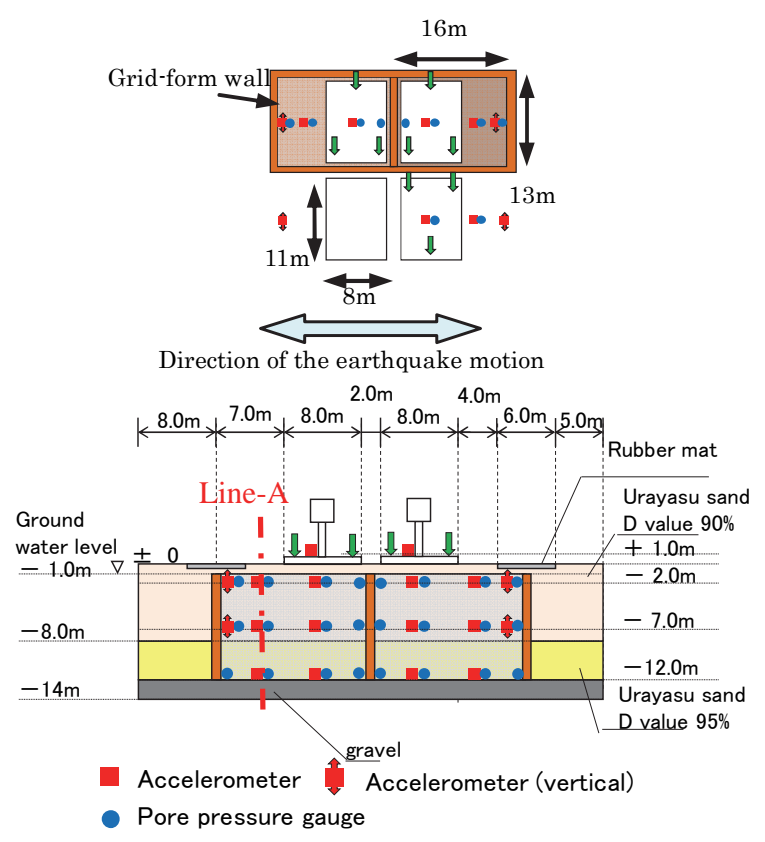

Fig. 18 Plan view and cross-section for Case-6 (the cross-section is the countermeasure side).

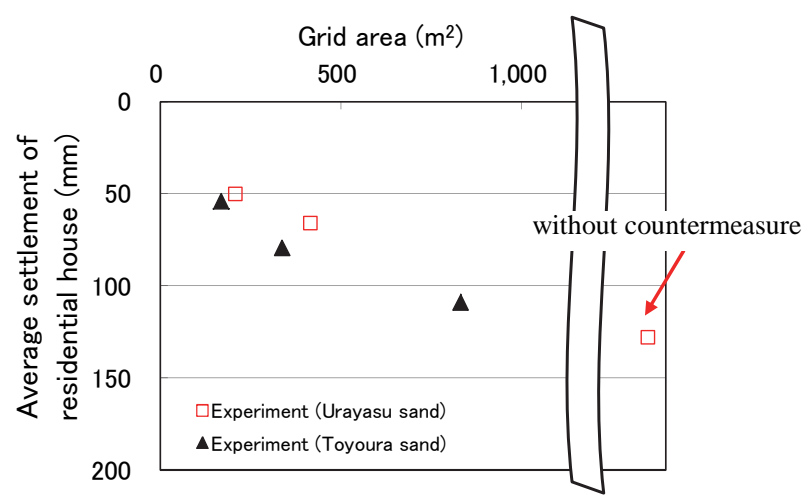

Fig. 19 Relationship between the grid area and the settlement of the residential house in the experiments.

$\times 20 \mathrm{~m}$ square grid was almost the same as the $416 \mathrm{~m}^{2}$ of the $32 \times 13 \mathrm{~m}$ rectangular grid. Furthermore, the average settlement of the $32 \times 13 \mathrm{~m}$ rectangular grid was $66 \mathrm{~mm}$, which was similar to that of the square area's average settlement. This shows that it is reasonable to arrange the experimental results according to the grid area, and therefore the grid area was adopted as a design guideline. 
Table 6 Soil parameter used in analysis.

\begin{tabular}{|cccccccc|}
\hline Stratum & $\begin{array}{c}\text { SPT-N } \\
\text { value }\end{array}$ & $\begin{array}{c}\text { Startum } \\
\text { thickness } \\
(\mathrm{m})\end{array}$ & $\begin{array}{c}\text { Content rate of } \\
\text { fine -grained } \\
\text { fraction }(\%)\end{array}$ & $\begin{array}{c}\text { Density } \\
\left(\mathrm{t} / \mathrm{m}^{3}\right)\end{array}$ & $\begin{array}{c}\text { Shear wave } \\
\text { velocity } \\
(\mathrm{m} / \mathrm{s})\end{array}$ & $\begin{array}{c}\text { Initial shear } \\
\text { modulus } \\
(\mathrm{kPa})\end{array}$ & $\begin{array}{c}\text { Poisson's } \\
\text { ratio }\end{array}$ \\
\hline Bs (dry) & 6 & 1 & 18 & 1.80 & 145 & 38,038 & 0.49 \\
Bs (saturated) & 6 & 1 & 18 & 1.80 & 145 & 38,038 & 0.49 \\
Fs & 4 & 6 & 22 & 1.80 & 127 & 29,029 & 0.49 \\
As1 & 15 & 2 & 21.9 & 1.80 & 197 & 70,067 & 0.49 \\
As2 & 7 & 2 & 31 & 1.70 & 153 & 39,813 & 0.49 \\
Ac1 & 2 & 20 & 93.6 & 1.50 & 133 & 26,534 & 0.49 \\
Ac2 & 14 & 15 & 93.6 & 1.50 & 220 & 72,600 & 0.49 \\
Ds & 74 & - & 10 & 2.00 & 388 & 301,088 & 0.49 \\
(engineering base) & & & & & & &
\end{tabular}
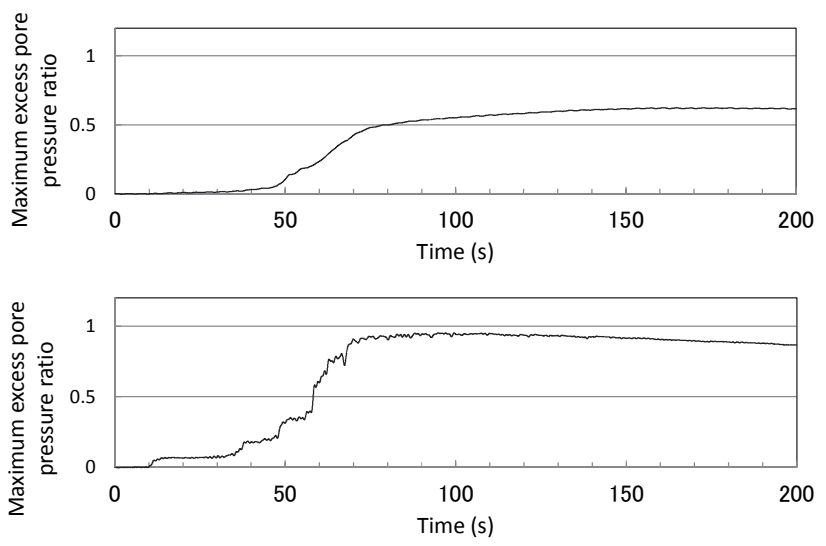

Fig. 20 Time history of excess pore pressure ratio(Case-6,Line-A).

The time histories of the excess pore pressure ratio at the GL-2 $\mathrm{m}$ and GL-12m measurement points, Line-A in Fig.18, are shown in Fig. 20. The maximum excess pore pressure ratio at GL-12 m was 0.95 , with a peak of approximately $70 \mathrm{~s}$ when the main input motion of the Urayasu Wave appeared. The maximum excess pore pressure ratio at GL-2 m was 0.57 , increasing to 0.50 at approximately $70 \mathrm{~s}$ when the main input motion appeared.

\section{(2) Analysis of the ground model}

An analysis of the ground model (shown in Fig. 16) was conducted using equivalent linear analysis. Table 6 shows the soil parameters in the analysis. The shear wave velocity $V_{\mathrm{s}}$ was calculated from SPT- $N$ value following the specifications for highway bridges ${ }^{14)}$. The equivalent linear analysis used dynamic properties determined from laboratory tests ${ }^{15),}{ }^{16)}$. The grid wall soil improvement was modeled using a quasi-three-dimensional model (Fig. 21). The quasi-three-dimensional model consisted of several two-dimensional sections. One section modeled the improved soil (orthogonal to the direction of the earthquake) and unimproved soil, and the other modeled the improved soil (direction of the earthquake motion). According to the boundary condition that the cross node of improved soil (or-

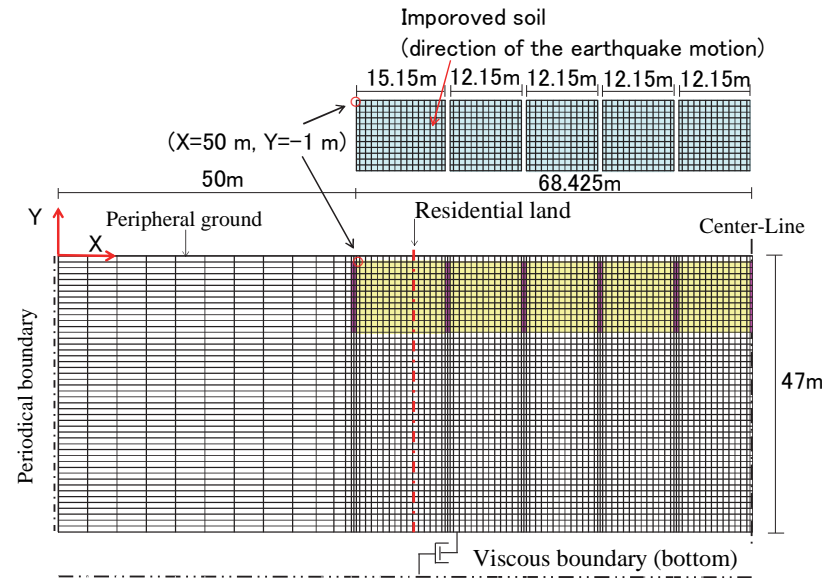

Fig. 21 Quasi-three-dimensional model

(1 grid for 1 residential land-area).

thogonal to the direction of the earthquake) and improved soil (direction of the earthquake motion) move in the same modes (Fig. 22), the three-dimensional shape of grid wall soil improvement was modeled using a two-dimensional analysis model. The analysis was conducted for the case without mitigation measures. The countermeasure analysis model changed the width $W$ of the soil improvement (orthogonal to the direction of the earthquake) and the length $L$ of the soil improvement (direction of the earthquake motion). $W$ and $L$ are defined in Fig. 22. The three analysis models for the countermeasures were one house within one grid (16 $\times 13 \mathrm{~m}$ grid), two houses within one grid $(32 \times 13 \mathrm{~m}$ grid), and four houses within one grid (32 $\times 26 \mathrm{~m}$ grid). In the analysis, the houses were not modeled.

The calculation by which FL was obtained in the unimproved soil is shown in Fig. 23.

Figures 24 and $\mathbf{2 5}$ show the distribution of the maximum horizontal acceleration and FL in the depth direction without mitigation measures. The peak ground acceleration was $1.43\left(\mathrm{~m} / \mathrm{s}^{2}\right)$ for a Yumenoshima wave and $1.91\left(\mathrm{~m} / \mathrm{s}^{2}\right)$ for 1.4 times the amplitude of a Yumenoshima wave. For both amplitudes, FL was below 1.0 for almost all sand layers.

In the quasi-three-dimensional analysis, the shear stress occurring within the liquefied ground of the 


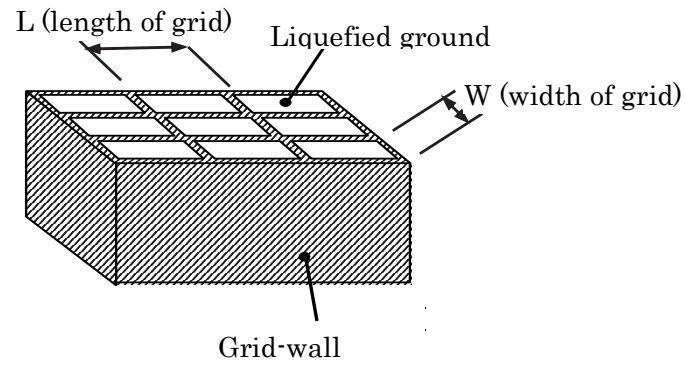

$\longleftrightarrow$ Direction of the earthquake motion

Quasi-three-dimensional model

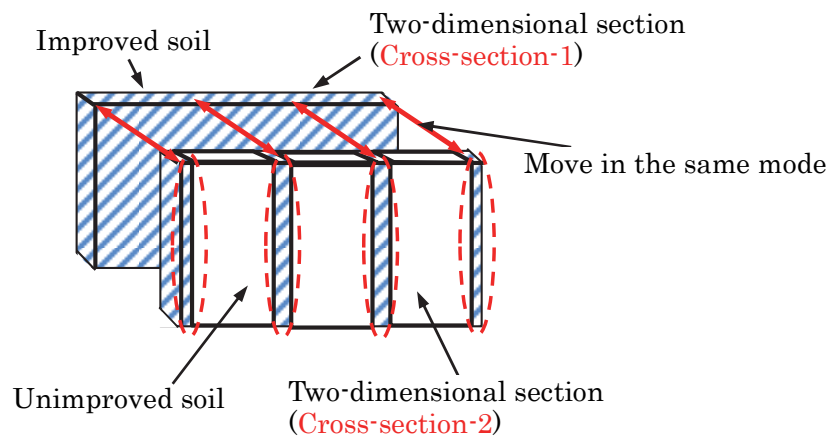

Fig. 22 Quasi-three-dimensional model (1 grid for 1 residential land-area).

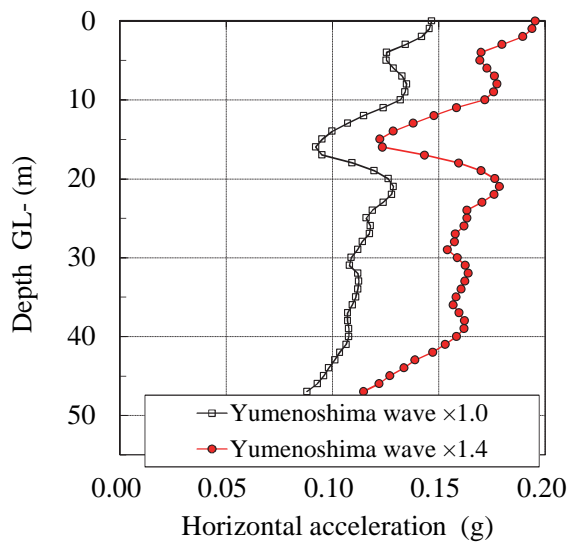

Fig. 24 Response acceleration (without mitigation measures).

grid wall soil improvement tended to underestimate values for cases with a high shear modulus of soil improvements. Therefore, a three-dimensional analysis was conducted (Fig. 26), for which the spacing of the grid walls soil improvement was $16 \times$ $13 \mathrm{~m}$, the same as for the quasi-three-dimensional analysis. The input motion was a Yumenoshima wave and the amplitude of the input motion was 1.4 times the Yumenoshima wave. Figure 27 compares the FL obtained with quasi-three-dimensional analysis and three-dimensional analysis. In quasi-three-dimensional analysis, the shear modulus of soil improvement adopted shear moduli which were reduced to $100 \%, 80 \%, 70 \%$, and $50 \%$ compared with the shear modulus used in the three-dimensional analysis. The FL obtained from the

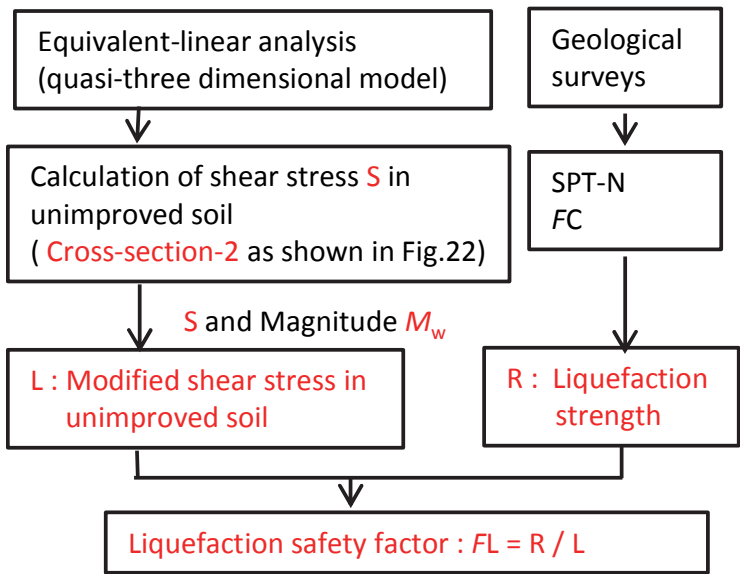

Fig. 23 Calculation process of FL using quasi-three-dimensional model.

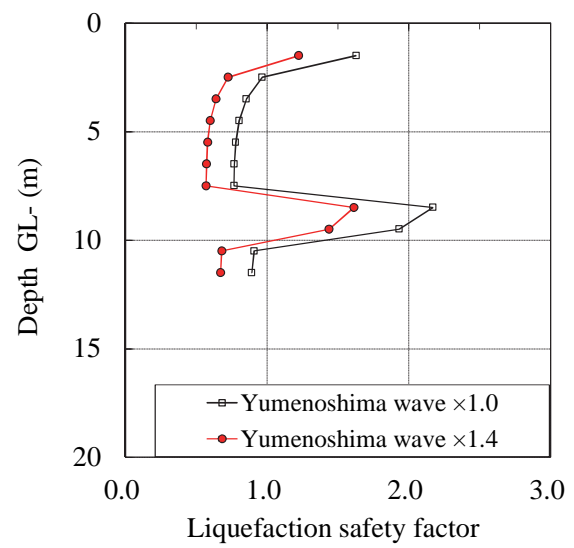

Fig. 25 Safty factor against liquefaction (without mitigation measures).

three-dimensional analysis was in good agreement with the quasi-three-dimensional analysis results, in which the shear modulus of improved soil was reduced to $70 \%$. Figure $\mathbf{2 8}$ compares the settlement of the residential house in the experiments (shown in Fig.19) and $D_{\text {cy }}$ obtained from quasi-three-dimensional analysis using a $70 \%$ shear modulus. The experimental results and analysis results exhibited good correspondence. In the design using equivalent linear analysis with a quasi-three-dimensional model, the shear modulus of improved soil adopted the shear modulus reduced to $70 \%$.

The time history of FL at GL-2.5 $\mathrm{m}$ and GL -11.5m was obtained via an analysis using a quasi-three-dimensional model with the shear modulus of improved soil reduced to $70 \%$. This is shown in Fig. 29. At GL-11.5 m, FL was below 1.0 approximately $20 \mathrm{~s}$ when the main input motion of the $\mathrm{Yu}$ menoshima wave appeared. At GL-2.5 m, the minimum value of $F L$ was observed at approximately 20s, though FL did not fail below 1.0. In the equivalent linear analysis, liquefaction was estimated from 


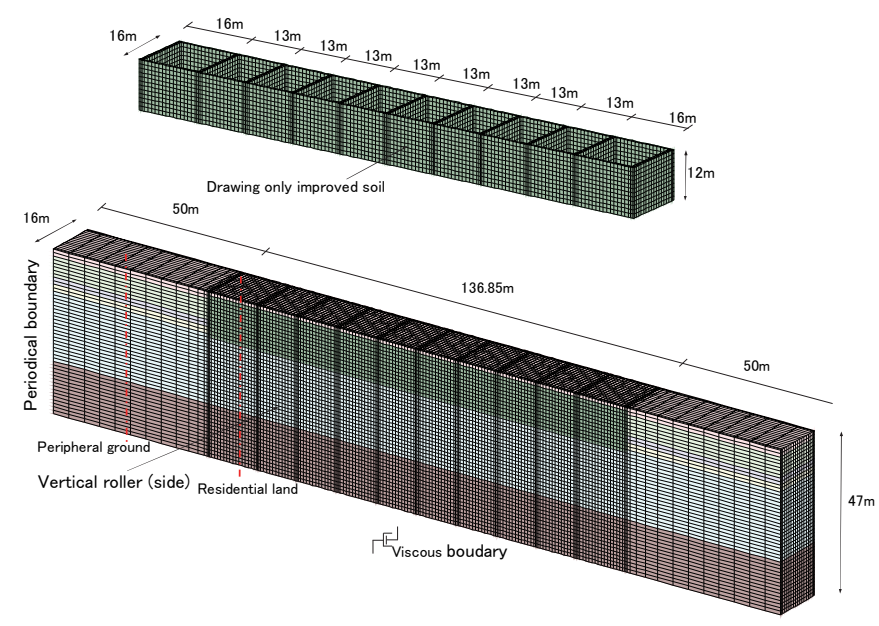

Fig. 26 Three-dimensional analysis model.

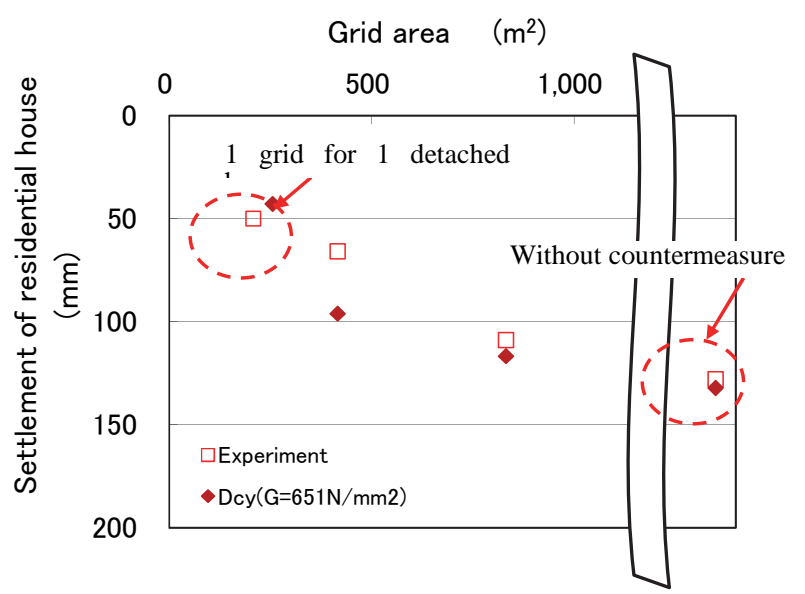

Fig. 28 Comparison of the settlement of a residential house Q3D between Q3D and experiments.

FL. The analysis and the dynamic centrifuge model test both used waves recorded at different observation points during the 2011 Tohoku earthquake. The increasing excess pore pressure ratio and the distribution of the maximum excess pore pressure at depth corresponded to those estimated by FL.

\section{DESIGN OF GRID WALL SOIL IM- PROVEMENTS IN C DISTRICT}

Using the analytical method mentioned in previous chapter, the design of grid wall soil improvements was conducted for 4,103 residential houses in 16 districts. This chapter will describe the design process for $\mathrm{C}$ district, focusing on the selection process of the specifications for grid wall soil improvements.

\section{(1) Site investigation}

Figure 30 shows a plan view of $\mathrm{C}$ district. C district was composed of 98 houses in 7 blocks. The

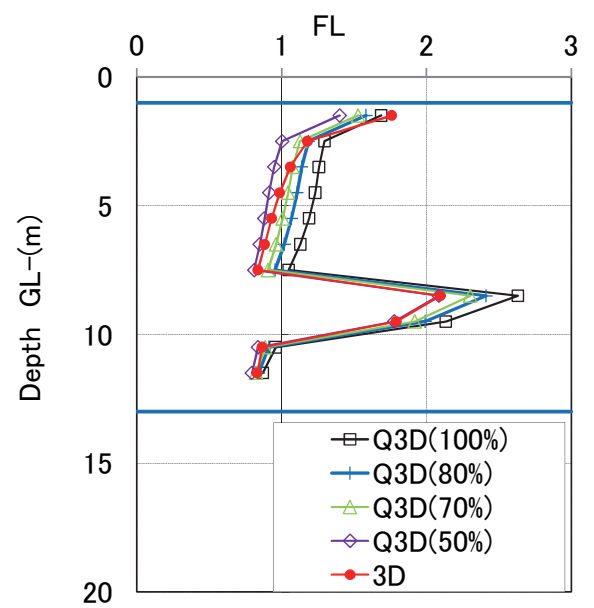

Fig. 27 Comparison of safety factor against liquefaction between the quasi-three-dimensional analysis model (Q3D) and the three-dimensional analysis model (3D).

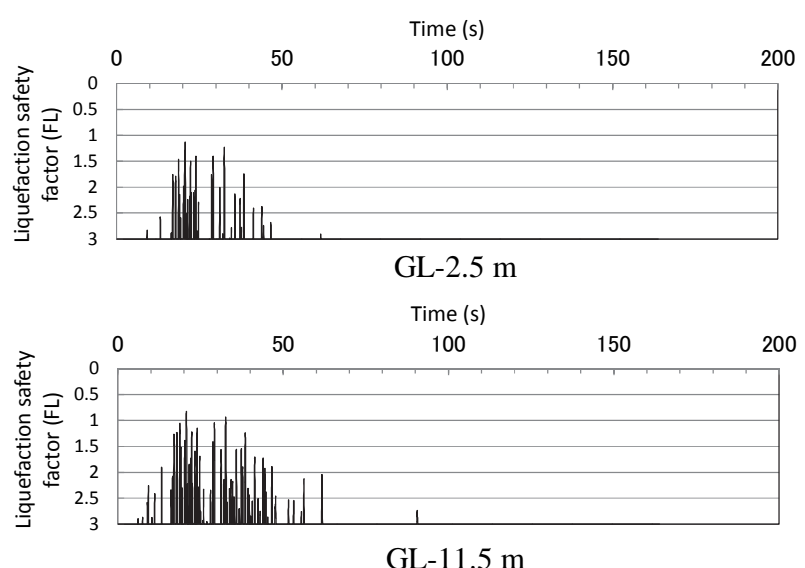

Fig. 29 Time history of liquefaction safety factor obtained by Q3D (16× 13 m grid).

items for site investigation were classified as 'residents' and 'roads.' For 'resident,' the spacing of the neighboring houses was measured and obstacles to construction of grid walls, such as walls and plants were investigated. Then, the construction plan for ground improvement was prepared, including plans to remove and recover the obstacles. For 'road', obstacles such as buried sewage pipes were surveyed with as-built drawings. A construction plan for grid wall soil improvements was also made while considering the possibility of removing buried sewage pipes. Figure 31 shows a construction plan view for grid wall soil improvement. The mechanical mixing method was used for construction on 'road.' A high-pressure injection mixing method was used for the construction of narrow spaces in the spacing of houses and roads. Figure 32 shows the relationship between the grid area and both the number of houses and accumulated houses.

\section{(2) Geological surveys}

Surveys with a standard penetration test (SPT) or a PDC test were conducted with 50 to 100 m distances. 
The liquefaction strength in a liquefied stratum was calculated using the SPT- $N$ value and the fine fraction content of soils was obtained from geological surveys.

Figure 30 shows the points of the geological surveys. The red circle shows the SPT test points, the blue rhomboids show the PDC test points. The categories of soil tests with the test specimens obtained from boreholes were physical characteristics, dynamic properties of ground, and cyclic triaxial tests. PS logging test was conducted at one location. Following the geological survey results, the stratum layers were estimated. Finally, three-dimensional computational-aided design data were defined for the geological strata.

Figure 33 shows the geological sections, which were the A-A' section and the B-B' section drawn in the plan view (shown in Fig. 30). The design analysis was conducted for the above two geological sections. C district was located at the center of Nakamachi, and the geological division was judged as the boundary between 'sand bar' and 'trough.' From the ground surface, stratum layers were divided into bank ( $B_{s}$ stratum), landfill ( $F_{s}$ and $F_{c}$ stratum) constructed with dredged soil until 5 to $6 \mathrm{~m}$ below ground level, and holocene sand $\left(\mathrm{A}_{\mathrm{s} 1}, \mathrm{~A}_{\mathrm{s} 2}\right.$, and $\left.\mathrm{A}_{\mathrm{sc}}\right)$ composed of natural deposits until 16 to $18 \mathrm{~m}$ below ground level (Fig. 33). The landfill cohesive stratum $\mathrm{F}_{\mathrm{c}}$ was confirmed to be the right part (southeast part) of cross-section B-B', and the landfill sand stratum $F_{s}$ was distributed at the left part (northwest part) of cross-section B-B.'

\section{(3) Design analysis for grid wall soil improve- ments}

For the two cross-sections shown in Fig. 33, quasi-three-dimensional analysis models were produced (shown in Fig. 34). The bottom boundary condition used a viscous boundary. The side boundary condition used an energy transfer boundary. In the design analysis, one analysis model section was represented with approximately 100 houses. Table 7 shows the soil parameters adopted in the design analysis. The shear wave velocity $V_{s}$ was determined by PS logging tests. The effective width of the grid walls was 0.85 $\mathrm{m}$ and the design strength of the improved soil wall was $f_{\mathrm{c}}=1.8\left(\mathrm{~N} / \mathrm{mm}^{2}\right)$. The initial shear modulus $G_{0}$ of the improved soil was determined based on the guidelines set by The Building Center of $\operatorname{Japan}^{16)}$. For the coefficient variation $V_{\text {quf }}=0.45$ of improved soil, the site strength of unconfined compression strength $q_{\text {uf }}$ was determined using the following equation:

$$
q_{\mathrm{uf}}=2.4 f_{\mathrm{c}}
$$

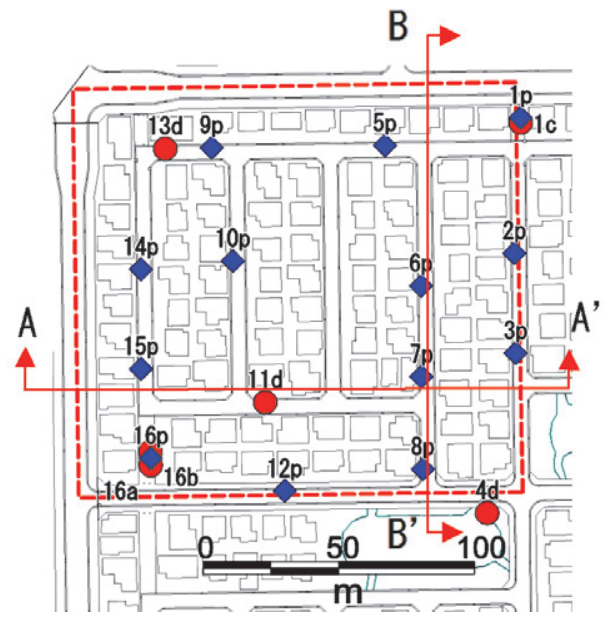

Fig. 30 Plan view of C district.

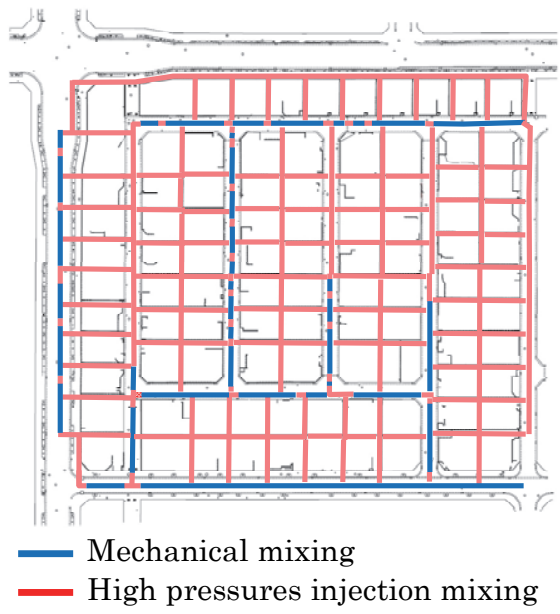

Fig. 31 A plan view of the construction plan of grid wall soil improvements.

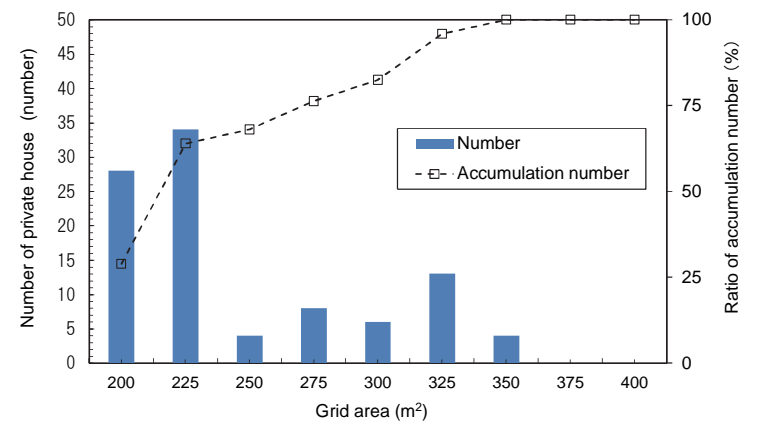

Fig. 32 Relationship between the grid area and the accumulation number of a residential house in $\mathrm{C}$ district.

In the sand stratum, the relationship between the Young's modulus of improved soil $E_{50}, E_{0}$, and $q_{\text {uf }}$ can be described by the following equations ${ }^{16)}$ :

$$
E_{50}=130 q_{\mathrm{uf}} \quad E_{50} / E_{0}=0.2
$$

Therefore, $G_{0}$ was determined from Poison's ratio $v$ $=0.26$ of the improved soil.

$$
G_{0}=258 \times 2.4 f_{\mathrm{c}}=619 f_{\mathrm{c}}
$$

For the condition of $f_{\mathrm{c}}=1.8\left(\mathrm{~N} / \mathrm{mm}^{2}\right), G_{0}=1114$ $\left(\mathrm{N} / \mathrm{mm}^{2}\right)$. 


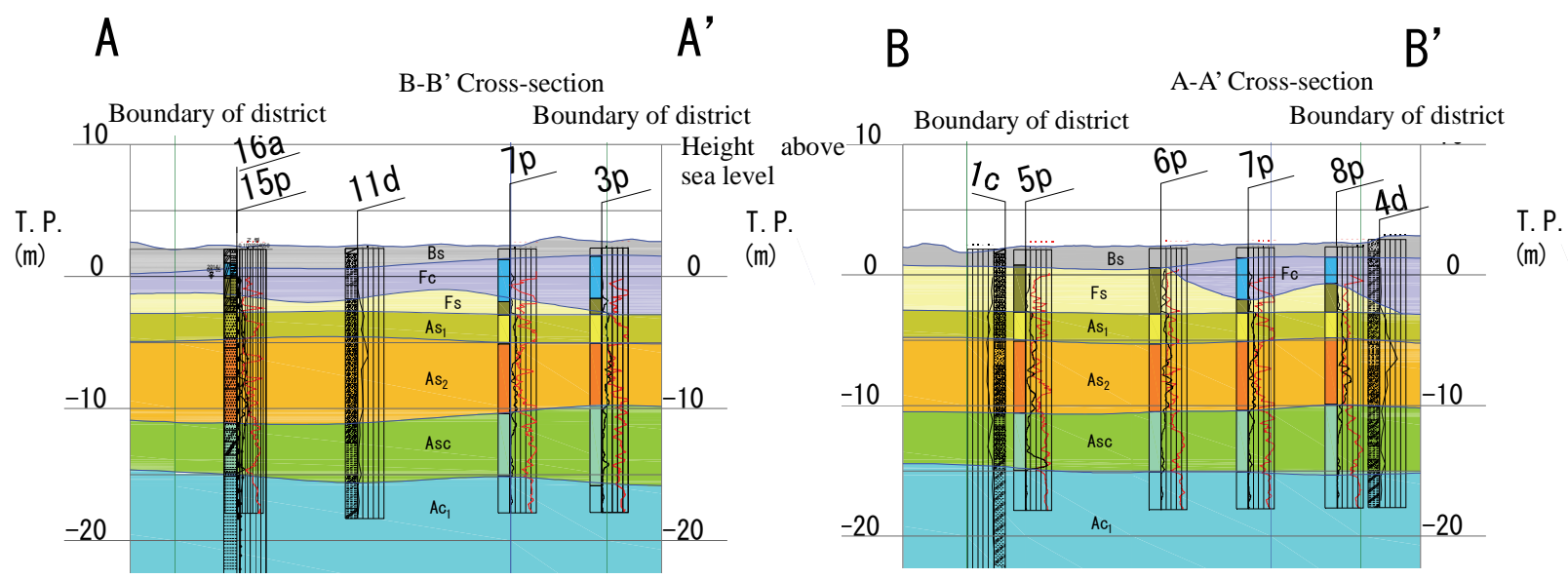

Fig. 33 Geological cross-section in C district.

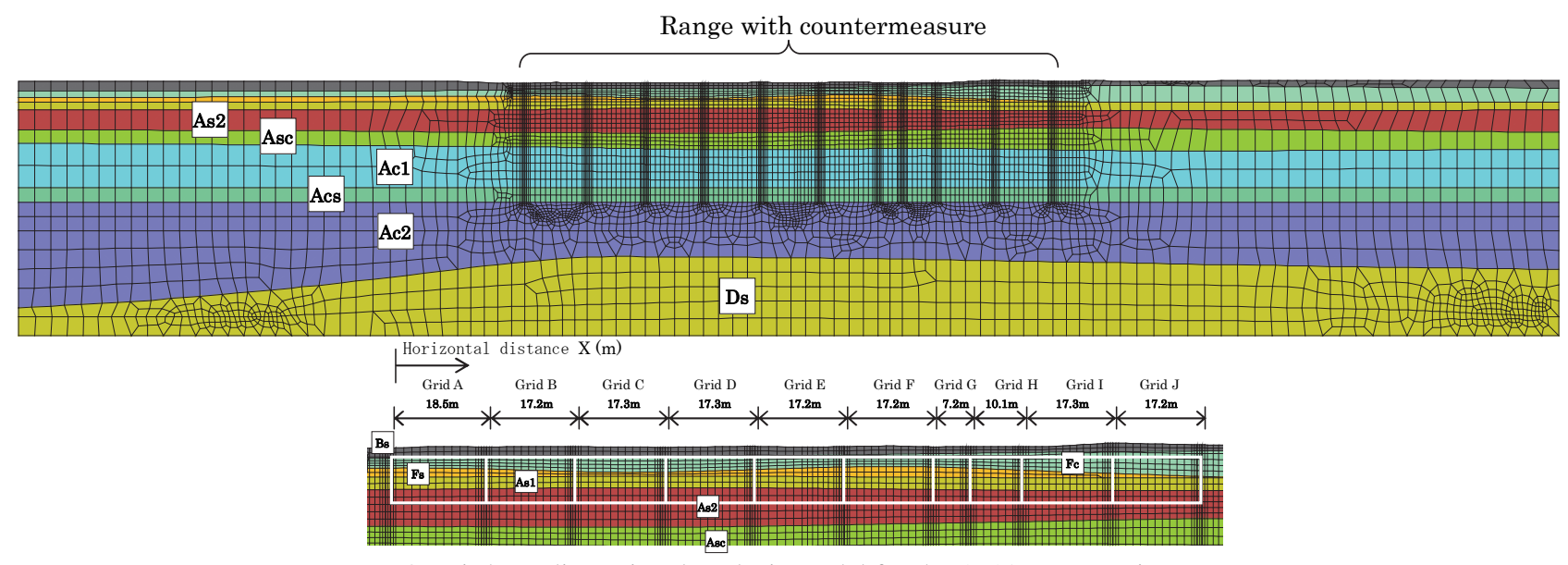

Quasi-three-dimensional analysis model for the A-A' cross section.

Range with countermeasure

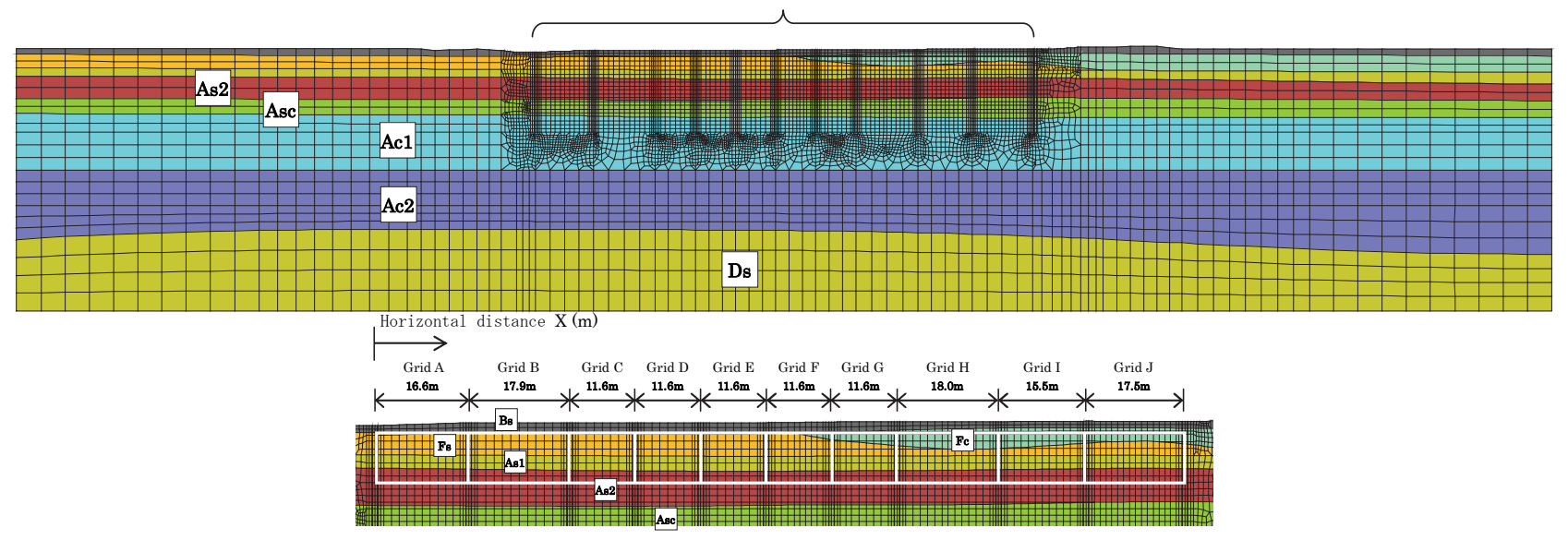

Quasi-three-dimensional analysis model for the B-B' cross section.

Fig. 34 Quasi-three-dimensional analysis models used in design analysis.

Based on the comparison of results between quasi-three-dimensional analysis and the three-dimensional analysis, it was necessary to reduce the value of $G_{0}$ used in the quasi-three-dimensional analysis by $70 \%$ from $G_{0}=1114\left(\mathrm{~N} / \mathrm{mm}^{2}\right)$. Therefore, the value of $G_{0}$ used in the design analysis was $781\left(\mathrm{~N} / \mathrm{mm}^{2}\right)$. The dynamic properties of the ground adopted the same properties shown in Fig. 13.
The equivalent linear analysis gave a maximum value of shear stress $\tau_{\max }$ at the center of liquefied ground within grid walls, and FL was determined from a comparison of the equivalent shear stress ratio obtained with the calculated $\tau_{\max }$ and the liquefaction strength. The magnitude $M_{\mathrm{w}}$ of a main target earthquake was considered in the calculation of the shear stress occurring on liquefied ground. The correction coefficient $\gamma_{\mathrm{n}}$ was set as $\gamma_{\mathrm{n}}=0.1\left(M_{\mathrm{w}}-1\right)=0.8$. In the 
calculation of FL, the liquefaction strength adopted was the average value of the liquefaction strength obtained from the SPT test and the PDC test for the following strata: $F_{s}, A_{s 1}$, and $A_{s 2}$.

The area of the residential houses was not the same area as shown in Fig. 32. The grid area was distributed from 200 to $400 \mathrm{~m}^{2}$. The relationship between the grid area and the settlement of a residential house shown in Fig. 19 was applied for the design of $\mathrm{C}$ district due to the plan shape of the grid wall area in $\mathrm{C}$ district. Therefore, the width of the quasi-three-dimensional model was set at various values, and estimating the possibility of liquefaction and evaluation of the improved soil for a distributed wide area of a residential house became possible. The depth of the gas pipe and water pipe buried from the road to the residential house was about $1 \mathrm{~m}$ below ground level. It is necessary to maintain sufficient

Table 7 Soil parameters used in design analysis for $\mathrm{C}$ district.

\begin{tabular}{|c|c|c|c|c|c|c|}
\hline Stratum & $\begin{array}{c}\gamma_{\mathrm{t}} \\
\left(\mathrm{kN} / \mathrm{m}^{3}\right)\end{array}$ & $\begin{array}{c}\gamma^{\prime} \\
\left(\mathrm{kN} / \mathrm{m}^{3}\right)\end{array}$ & $\begin{array}{c}\rho \\
\left(\mathrm{kg} / \mathrm{m}^{3}\right)\end{array}$ & $\begin{array}{l}\text { Vs } \\
(\mathrm{m} / \mathrm{s})\end{array}$ & $v$ & $\begin{array}{c}\mathrm{G}_{0} \\
\left(\mathrm{MN} / \mathrm{m}^{2}\right)\end{array}$ \\
\hline Bs & 19.0 & 9.0 & 1.937 & 120 & 0.489 & 27.9 \\
\hline Fc & 15.5 & 5.5 & 1.581 & 120 & 0.489 & 22.8 \\
\hline Fs & 19.0 & 9.0 & 1.937 & 170 & 0.488 & 56.0 \\
\hline As1 & 19.0 & 9.0 & 1.937 & 170 & 0.488 & 56.0 \\
\hline As2 & 19.0 & 9.0 & 1.937 & 170 & 0.488 & 56.0 \\
\hline Asc & 18.0 & 8.0 & 1.835 & 130 & 0.496 & 31.0 \\
\hline Ac1 & 16.0 & 6.0 & 1.632 & 130 & 0.496 & 27.6 \\
\hline Acs & 16.5 & 6.5 & 1.683 & 150 & 0.495 & 37.9 \\
\hline Ac2(1) & 16.0 & 6.0 & 1.632 & 150 & 0.491 & 36.7 \\
\hline Ac2(2) & 16.0 & 6.0 & 1.632 & 200 & 0.491 & 65.3 \\
\hline Ds & 18.5 & 8.5 & 1.886 & 310 & 0.480 & 181.3 \\
\hline $\begin{array}{l}\text { Improved } \\
\text { soil }\end{array}$ & 20.0 & 10.0 & 2.041 & - & 0.260 & 781.0 \\
\hline
\end{tabular}

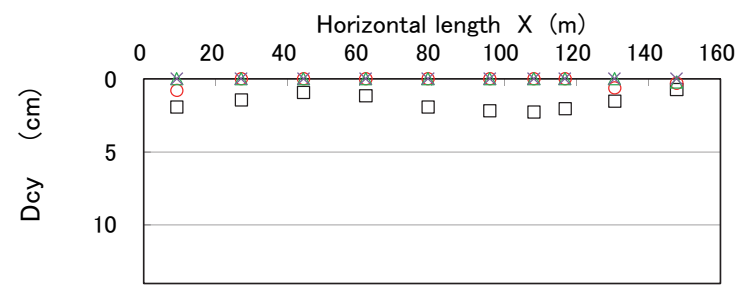

Fig. $35 D_{\text {cy }}$ and $H_{1}$ for the A-A' cross section (width of analysis $=18 \mathrm{~m}$ ).

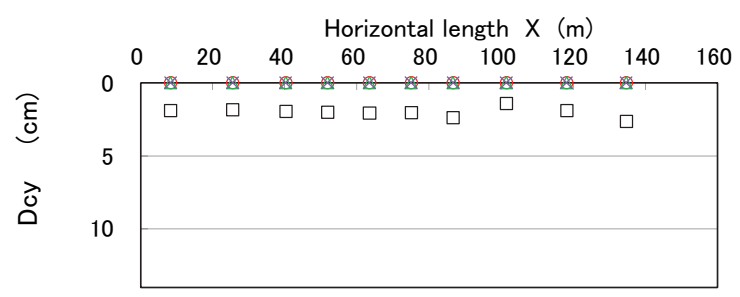

spacing between pipes and the top of the grid wall during construction. The high-pressure injection mixing also requires a $1.5 \mathrm{~m}$ overburden from ground level. Therefore, the top of the grid wall was set at $1.5 \mathrm{~m}$ below ground level. Since the bottom depth of the grid wall was determined to satisfy the design guideline shown in Table 2, design analysis was conducted with the quasi-three-dimensional model where the bottom depths of the grid wall were 10,11 , and $12 \mathrm{~m}$ below ground level.

Figures 35 and 36 show the horizontal distribution with $D_{\text {cy }}$ and the thickness of the non-liquefied layer $H_{1}$ for the A-A' cross-section and the B-B' cross -section, respectively. In the case without mitigation measures, the design guideline was not satisfied because $H_{1}$ was within $5.0 \mathrm{~m}$. After installation of countermeasures with grid wall soil improvement, it was confirmed that the design guideline was satisfied for a sufficient depth of the grid wall.

Figure 37 shows the distribution of $F L$ in the depth direction and the maximum shear stress that occurred for the improved soil. In cases where the bottom depth of the grid wall was $10 \mathrm{~m}$ below ground level, against a main target earthquake, FL exceeded 1.0 for all depths of the liquefied layer. For the main target earthquake, FL fell below 1.0 only in the Fs stratum without countermeasures. However, to ensure that $F L$ exceeds 1.0 with countermeasures, the bottom of the grid wall must be designed in the $A_{\mathrm{s} 2}$ stratum (GL-10 m). Furthermore, shear stress for the improved soil was within the design guidelines. The

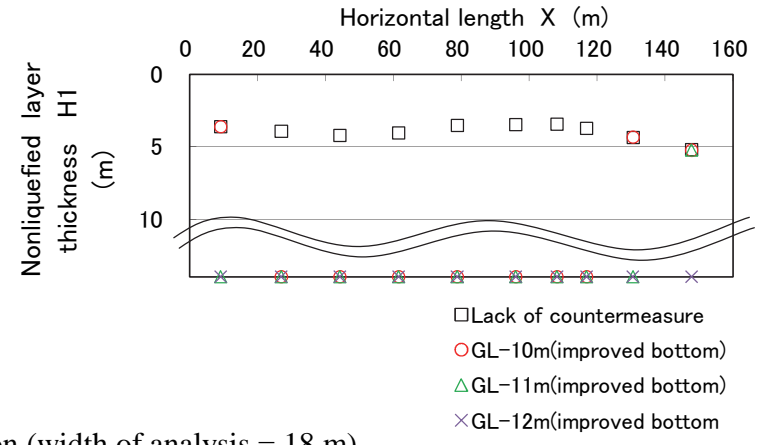

Fig. $36 D_{\text {cy }}$ and $H_{1}$ for B-B' cross section (width of analysis = $17.2 \mathrm{~m}$ ). 


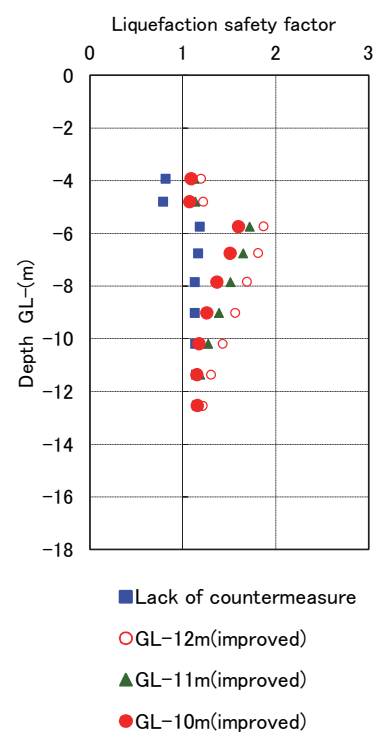

Main target earthquake
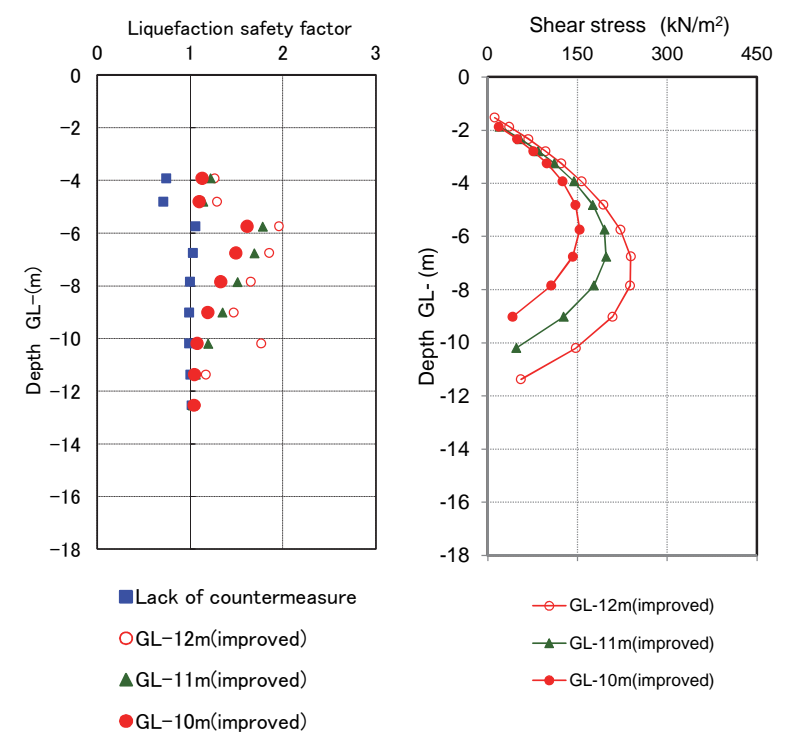

Level 2 earthquake

Fig. 37 Safety factor against liquefaction and maximum shear stress distribution in the depth direction (A-A' cross section, grid-F).

allowable stress $\tau_{\mathrm{a}}$ of the improved soil was adopted as $30 \%$ of $f_{\text {c }}$. A safety factor of $2 / 3$ was adopted for a main target earthquake and $3 / 3$ for a level 2 earthquake. Following these conditions, $\tau_{\mathrm{a}}$ was $360 \mathrm{kPa}$ for a main target earthquake and $540 \mathrm{kPa}$ for a level 2 earthquake. Figure 38 shows the relationship between the grid area and the minimum value of $F \mathrm{~L}$ for each grid obtained from the analysis results with the bottom depth of improved soil at $10 \mathrm{~m}$ below ground level. Within a grid area of $350 \mathrm{~m}^{2}$, it was confirmed that the minimum value of FL exceeded 1.0. The bottom depth of the grid wall in $\mathrm{C}$ district was determined to satisfy the design guideline, i.e., a value of FL that exceeds 1.0 for all liquefied layers. The plan distribution of the bottom depth of the grid wall shown in Fig. 39 was determined to properly consider the analysis results and geological characteristics.

\section{CONCLUSIONS}

The damaged area in Urayasu was constructed using hydraulic dredging from 1965 to 1980 . During the 2011 Tohoku earthquake, the occurrence of liquefaction in the $F_{s}$ stratum and the $A_{s}$ stratum was the main reason for damage to residential houses. In particular, the occurrence of liquefaction in the $F_{s}$ stratum was confirmed for a main target earthquake for every district in the design analysis. Conversely, the occurrence of liquefaction in the $A_{s 1}$ stratum only occurred in four districts and liquefaction in the $A_{s 2}$ stratum was only observed in two districts. A design of grid wall soil improvement was conducted for 4,103 residential houses where severe damage oc- curred due to liquefaction. The design guidelines adopted the following two items: (1) During a main target earthquake at the same level as that of the 2011 Tohoku earthquake, no obvious damage should occur in a residential house. (2) For a level 2 earthquake, liquefaction be tolerable, but the stress level in the improved soil should be below the allowable value: i.e. the shear stress of a grid wall must not exceed the permissible value. The requirement for improved soil in a main target earthquake must be satisfied even after the occurrence of a level 2 earthquake.

The performance, where no obvious damage occurs in a residential house, was defined as a safety factor against liquefaction that exceeds 1.0 for all liquefied strata, or a $H_{1}$ value (thickness of the non-liquefied layer from ground level) that exceeds $5.0 \mathrm{~m}$ and a $D_{\text {cy }}$ value (index of settlement due to liquefaction based on the Recommendation for Design of Building Foundations) that does not exceed 5 $\mathrm{cm}$. This performance guideline was confirmed with analysis results obtained by equivalent linear analysis using a quasi-three-dimensional model. The verification of analytical results was conducted based on the equivalent linear simulation analysis using a three-dimensional model for dynamic centrifuge tests. Consequently, in design analysis, the shear modulus $G_{0}$ of the improved soil had to be reduced by $70 \%$ for the spacing between the grid walls and the geological characteristics of the 16 districts. For the various areas of residential houses, the effectiveness of the design method using various widths of quasi-three-dimensional analysis model was confirmed. The design guidelines adopted the grid area and did not adopt the spacing between the grid walls. 


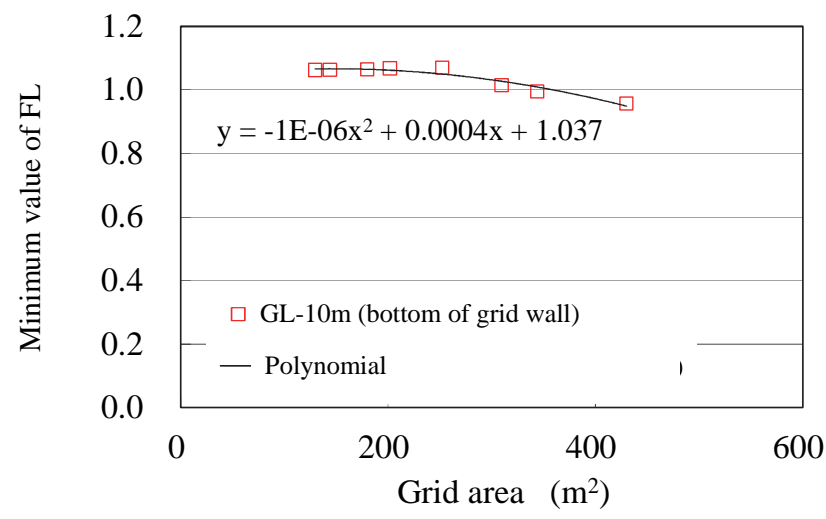

Fig. 38 Relationship betwenn the grid area and the minimum liquefaction safety factor (bottom of grid wall = GL-10 m).

The validity of the design guidelines was confirmed using dynamic centrifuge model tests where the plan shapes of grid form were square $(20 \times 20 \mathrm{~m})$ and rectangular $(32 \times 13 \mathrm{~m}$ grid $)$.

ACKNOWLEDGMENTS: The authors express their gratitude to the members of the Urayasu Committee. The authors also express their gratitude to the National Research Institute for Earth Science and Disaster Prevention for permitting them to download material on Urayasu Wave from their website for the purposes of this study.

\section{REFERENCES}

1) Ministry of Land, Infrastructure, Transport and Tourism Urban-Safety Affairs Division: The city area liquefaction measures promotion guidance, 2014 (in Japanese).

2) Cooperative Research Reports of PWRI: Design and Construction Manual of Countermeasures Against Liquefaction, Vol. 186, 1999 (in Japanese).

3) Koga, Y., Matsuo, O., Enokida, M., Ito, K. and Suzuki, Y.: Shaking table test on DMM method as a countermeasure against liquefaction of sandy ground (Part 2) Effects of improved ground in grid configuration against liquefaction, The 23th Japan National Conference on Soil Mechanics and Foundation Engineering, pp. 1019-1020, 1988 (in Japanese).

4) Uchida, A., Odajima, N. and Yamashita, K.: Performance of building foundation with grid-form ground improvement during the 2011 Tohoku Pacific Earthquake, AIJ Journal of Technology and Design, Vol. 19, No. 42, pp. 481-484, 2012 (in Japanese).

5) Architectural Institute of Japan: Recommendations for Design of Building Foundations, pp. 62, 2001 (in Japanese).

6) Suzuki, Y., Saito, S., Onimaru, S., Kimura, T., Uchida, A. and Okumura, R.: Grid-shaped stabilized ground improved by deep cement mixing method against liquefaction for a

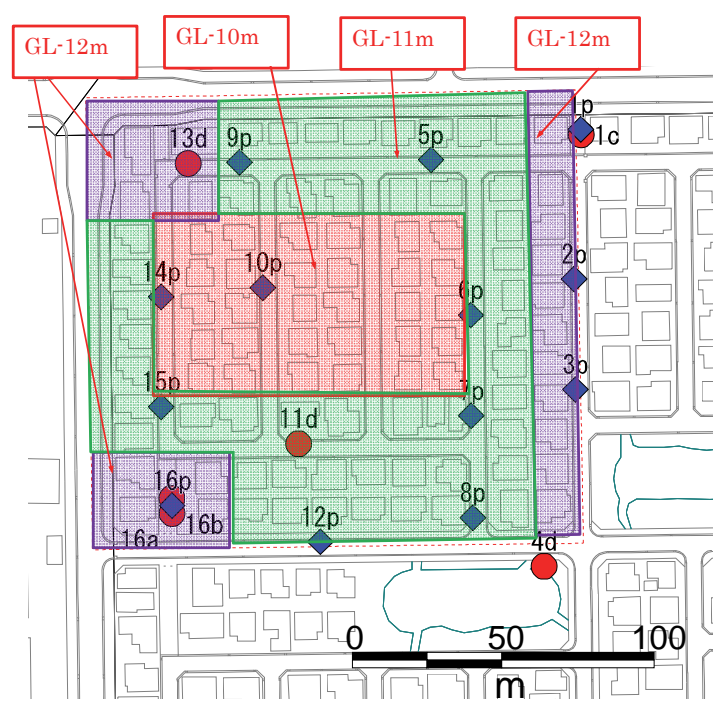

Fig. 39 Plan view with bottom depth of grid-wall.

building foundation, Tsuchi-to-Kiso, JGS, Vol. 43, No. 3, pp. 46-49, 1996 (in Japanese).

7) Uchida, A., Odajima, N. and Yamashita, K.: Performance of piled raft foundation with grid-form ground improvement during the 2011 off the Pacific Coast of Tohoku Earthquake, Journal of Disaster Research, Vol. 7, No. 6, pp. 726-732, 2012.

8) Tsukuni, S., Uchida, A., Honda, T. and Konishi, K: Dynamic centrifuge model test focused on settlement of the residence improved with grid-form deep mixing walls, Japanese Geotechnical Journal, Vol. 9, No. 4, pp. 761-771, 2014 (in Japanese).

9) Sawada, S.: Evaluation of differential settlement following liquefaction using Piezo Drive Cone, 17th International Conference on Geotechnical Engineering, Alexandria, Egypt, pp. 1064-1067, 2009.

10) Website of Urayasu City, Urayasu Committee Report, http://www.city.urayasu.lg.jp/_res/projects/default_project/ _page_/001/013/135/siryou3.pdf, Referred 2016.6.29. (in Japanese)

11) Ishihara, K.: Stability of natural deposits during earthquake, Proc., 11th Int. Conf. on Soil Mechanics and Foundation Engineering, Vol. 1, pp. 321-376, 1985.

12) Architectural Institute of Japan: Recommendations for Design of Building Foundations, pp. 66, 2001 (in Japanese).

13) Tsukuni, S., Uchida, A. and Konishi, K.: Effect of grid-form deep mixing walls to prevent liquefaction damage of small houses, Deep Mixing 2015, San Francisco, 2015.

14) Japan Road Association: Specifications for Highway Bridges, PART V Seismic Design, 2002.

15) Website of Urayasu City, Urayasu Committee Report, http://www.city.urayasu.lg.jp/_res/projects/default_project/ _page_/001/002/934/lasthoukoku02-02.pdf, Referred 2016. 6.29. (in Japanese)

16) The Building Center of Japan: Design and Quality Control Guidance of Improved Soil for Building, Revised edition, 2002 (in Japanese).

(Received March 30, 2016) 